\title{
Direct synthesis of bulk AIPON basic catalysts in ionic liquids
}

Ana I. Saugar, Carlos Márquez-Alvarez and Joaquín Pérez-Pariente*

Instituto de Catálisis y Petroleoquímica, ICP-CSIC, C/ Marie Curie 2, 28049-Madrid, Spain

*Corresponding author: jperez@icp.csic.es

\begin{abstract}
In this work, the direct synthesis of materials formed by a network of $\mathrm{Al}, \mathrm{P}, \mathrm{N}$ and $\mathrm{O}$ atoms (AlPON) from the ammonolysis of $\mathrm{P}$ and $\mathrm{N}$ molecular precursors in an ionic liquid is reported. The as-made samples can be treated under ammonia at high temperature to remove the ionic liquid retained after synthesis. The resulting amorphous materials have high porosity and surface area. The $\mathrm{P}$ atoms of the skeleton are involved in single and double bonds with $\mathrm{N}$ atoms, whereas bridged - NH- and terminal P-NH2 groups are also present. However, no evidence for Al-N bonds has been found. It has been shown by pyrrole adsorption that these materials exhibit basic properties, showing a basic strength higher than that of $\mathrm{Si}-\mathrm{N}$ materials, but weaker than hydrotalcites. Nevertheless, they are active and very selective catalysts for the Michael addition reaction between malononitrile and chalcone.
\end{abstract}

Keywords: AlPON, basicity, Michael reaction, pyrrole, ionic liquid. 


\section{Introduction}

The replacement of oxygen atoms by nitrogen atoms in the framework of high surface area aluminophosphate materials has been a subject of continuous interest aiming at the preparation of solids that could behave as selective catalysts in base-catalyzed reactions. The preferred method to accomplish that goal has been traditionally the post-synthesis treatment of aluminophosphate materials with ammonia at high temperature, a procedure that was initially applied for the nitridation of phosphate glasses [1, 2]. In this way, the nitridation of amorphous $\mathrm{AlPO}_{4}$ with high surface area led to materials that show basic properties and are able to catalyze the Knoevenagel condensation reaction between benzaldehyde and malononitrile [3-5], a behavior that has also been reported for nitrided ordered mesoporous aluminophosphate [6]. The early works on the nitridation of phosphate glasses also inspired a similar high-temperature treatment with ammonia of the crystalline microporous aluminophosphate AlPO-5 [7]. The nitridation of amorphous aluminophosphate is usually carried out under ammonia flow at high temperature, normally $800^{\circ} \mathrm{C}$, and long period of time in order to replace a significant amount of oxygen by nitrogen. Nevertheless, large amounts of oxygen atoms are still present in the samples in spite of this treatment $[4,5,8]$. Moreover, it could be expected that the nature of the chemical environment of the nitrogen atoms incorporated in the material would be affected by the severity of the nitridation conditions, as well as the relative proportion of these environments.

It has been reported recently a new solvothermal route for the preparation of siliconnitrogen materials by the ammonolysis of silicon tetrachloride in ionic liquids under mild conditions [9]. Moreover, this procedure has been further extended to the preparation of ( $\mathrm{Si}, \mathrm{Al}) \mathrm{N}$ materials, which exhibit basic properties and are able to catalyze 
in a very efficient and selective manner the Michael addition reaction between the donor malononitrile and the acceptor chalcone [10]. In this work, this solvothermal route has been followed to prepare high-surface area AlPON materials, which have been characterized by a variety of techniques in order to shed light on the chemical environment of the several atoms present in the materials. Moreover, the basic character of these materials has been tested by pyrrole adsorption and their activity in the Michael reaction has been also explored. Although the Knoevenagel condensation has been the reaction of choice for testing the activity in base catalysis of most if not all the AlPON materials referred to above, it has to be considered that water is also produced along with the desired condensation product. However, the nitride materials are sensitive to water [11], and it might well be possible therefore that its presence in the reaction media affects the reaction outcome. For this reason, the Michael addition reaction has been preferred for catalysts testing, added to the fact that this base-catalyzed reaction, leading to the formation of carbon-carbon bonds, is very useful for the synthesis of a variety of chemical compounds $[12,13]$.

\section{Experimental}

The phosphorus-aluminum oxyimide gels were prepared under anaerobic conditions through the use of an air-free system by a modification of our previously reported method [9]. First, $4.29 \mathrm{~g} \mathrm{(7.0} \mathrm{mmol)} \mathrm{of} \mathrm{phosphoryl} \mathrm{chloride} \mathrm{(Sigma-Aldrich,} \geq 99 \mathrm{wt} \%$ ) and $3.73 \mathrm{~g}(7.0 \mathrm{mmol})$ of anhydrous aluminium chloride (Panreac, $98 \mathrm{wt} \%)$ were dissolved in $31.7 \mathrm{~g}$ of the ionic liquid 1-ethyl-3-methylimidazolium bis(trifluoromethylsulfonyl)imide $\left(\left[\mathrm{C}_{2} \mathrm{C}_{1} \mathrm{im}\right]\left[\mathrm{Tf}_{2} \mathrm{~N}\right]\right)$ (Sigma-Aldrich, $\left.98 \mathrm{wt} \%\right)$ and 
reacted with gaseous anhydrous ammonia (Air Liquide, $\mathrm{H}_{2} \mathrm{O}<400 \mathrm{ppm}$ ) in a vessel kept in an ice bath to prevent a very vigorous course of the reaction.

The resulting phosphorus-aluminum oxyimide gel was homogenized inside a nitrogenfilled glove bag and introduced into 60-ml Teflon-lined stainless steel autoclaves which were heated statically at $180{ }^{\circ} \mathrm{C}$ under autogenous pressure for 14 days or 28 days. In some experiments, pyrrolidine (Sigma-Aldrich, $\geq 99.5 \mathrm{wt} \%$, purified by distillation) was added to the mixture and ammonia gas was dissolved in the ionic liquid before the heating process. To dissolve the ammonia, static phase equilibrium cells constructed with Swagelok fittings, one Swagelok ball valve, and glass-lined stainless steel tubing were used. The cells were filled inside the glove bag with the mixture resulting of homogenizing the white gel obtained in the ammonolysis reaction, adding pyrrolidine in some cases. Then, ammonia was dissolved in the ionic liquid by the procedure described in our previous report [9] and the cells were heated as described above.

The obtained products were washed with methanol (Scharlau, $0.028 \%$ water as received; it was distilled prior to use in the presence of activated molecular sieve $3 \AA$ pellets to remove the traces of water) to remove the ammonium chloride, the ionic liquid and the unreacted pyrrolidine if present, and filtered under a nitrogen flow using a stainless steel pressure filter holder with a nylon membrane disc filter ( 0.45 micron pore-size). The transfer of the products to the filter holder was performed always in the glove bag, as well as all subsequent manipulations of the washed product. White solids were obtained in all cases. After washing, the samples were heated under flowing ammonia $(100 \mathrm{ml} / \mathrm{min})$ at $600{ }^{\circ} \mathrm{C}$ for $2 \mathrm{~h}$ to remove compounds trapped in the pores of the materials. 
In this way, different gels with the starting molar composition $1 \mathrm{OPCl}_{3}: 1 \mathrm{AlCl}_{3}: x \mathrm{Py}$ : 2.8 [ $\left.\mathrm{C}_{2} \mathrm{C}_{1} \mathrm{im}\right]\left[\mathrm{Tf}_{2} \mathrm{~N}\right]: y \mathrm{NH}_{3}$ were prepared, where $x$ and $y$ were varied as stated in Table 1. Hereafter the samples will be named making reference to the quantity of pyrrolidine (Py), $x P y$, where $x$ stands for the Py/P molar ratio, followed by a number indicating the heating time. If ammonia is dissolved in the ionic liquid, the heating time is followed by NH. As an example, AlP-2Py-14d-NH refers to the sample prepared from a phosphorusaluminum oxyimide gel with a Py/P molar ratio of 2 heated at $180^{\circ} \mathrm{C}$ for 14 days with ammonia dissolved in the ionic liquid. The experiments performed are summarized in Table 1.

Thermogravimetric analyses of the as-prepared samples were performed in a PerkinElmer TGA7 instrument, in an air flow of $40 \mathrm{~mL} / \mathrm{min}$, with a heating ramp from 25 to $900{ }^{\circ} \mathrm{C}$ at $20^{\circ} \mathrm{C} / \mathrm{min}$.

CHNS elemental analyses were obtained in a LECO CHNS-932 analyser provided with an AD-4 Perkin-Elmer scale. The phosphorus and aluminum content of the samples were measured by ICP-OES using a Perkin-Elmer Optima 3300 DV spectrometer. Samples for ICP-OES analysis were dissolved by alkaline fusion.

MAS NMR spectra were recorded with a Bruker AV 400 WB spectrometer operating at 104.26 and 161.97 MHz for registering ${ }^{27} \mathrm{Al}$ and ${ }^{31} \mathrm{P}$ spectra, respectively. A $4 \mathrm{~mm}$ probe with a $\mathrm{ZrO}_{2}$ rotor and a KeI-F tap operating at a spinning rate of $10 \mathrm{kHz}$ were used for all spectra. ${ }^{27} \mathrm{Al}$ MAS NMR spectra were acquired by applying pulse length of $0.4 \mu$ s corresponding to a flip angle of $\pi / 30$ and using a pulse delay of $2 \mathrm{~s}$. The applied pulse length in the ${ }^{31} \mathrm{P}$ MAS NMR spectra was $3 \mu$ s corresponding to a flip angle of $\pi / 4$ and the pulse delay was $100 \mathrm{~s}$. The ${ }^{27} \mathrm{Al}$ chemical shifts were referenced to a $0.1 \mathrm{M}$ $\mathrm{Al}\left(\mathrm{NO}_{3}\right)_{3}$ aqueous solution $(\delta=0 \mathrm{ppm})$ using $\mathrm{Al}\left(\mathrm{SO}_{4}\right)_{2}\left(\mathrm{NH}_{4}\right) \cdot 12 \mathrm{H}_{2} \mathrm{O}(\delta=-0.4 \mathrm{ppm})$ as 
secondary reference. The ${ }^{31} \mathrm{P}$ chemical shifts were referenced to a $85 \mathrm{wt} \% \mathrm{H}_{3} \mathrm{PO}_{4}$ aqueous solution $(\delta=0 \mathrm{ppm})$ using $\left(\mathrm{NH}_{4}\right) \mathrm{H}_{2} \mathrm{PO}_{4}(\delta=0.81 \mathrm{ppm})$ as secondary reference. For all the NMR measurements the samples were prepared in a nitrogen-filled glove bag.

Attenuated total reflection Fourier transform infrared (ATR-FTIR) measurements were conducted using a Nicolet Nexus 670 spectrometer provided with a MCT detector and a GladiATR single-bounce monolithic diamond ATR accessory. The spectra were recorded in the $4000-400 \mathrm{~cm}^{-1}$ range, at $4 \mathrm{~cm}^{-1}$ resolution, by averaging 128 scans.

Nitrogen adsorption-desorption isotherms where measured in a Micromeritics ASAP 2420 apparatus at the temperature of liquid nitrogen $\left(-196^{\circ} \mathrm{C}\right)$. The samples $(\sim 100 \mathrm{mg})$ were loaded in the sample tubes in a nitrogen-filled glove bag and degassed in situ at $350{ }^{\circ} \mathrm{C}$ in vacuum for 16 hours prior to analysis. Surface areas were determined using the BET method and the external and micropore surface areas were calculated using the t-plot method. The pore volume and the average pore diameter were calculated by applying the $\mathrm{BJH}$ protocol to the adsorption branch of the isotherm.

X-ray photoelectron spectroscopy (XPS) analysis was performed using a SPECS GmbH spectrometer equipped with a PHOIBOS 150 9MCD energy analyzer. A nonmonochromatic magnesium X-ray source $(1253.6 \mathrm{eV})$ was used with a power of $200 \mathrm{~W}$ and voltage of $12 \mathrm{kV}$. The powder sample was pressed inside a nitrogen-filled glove bag using a hand press and stuck on the sample holder with double-sided adhesive conductive carbon tape. The sample was introduced into the spectrometer without prior thermal treatment. The instrument operated at pressures near $6 \times 10^{-9} \mathrm{mbar}$ in the analysis chamber. Pass energies of 75 and $25 \mathrm{eV}$ were used for acquiring both survey and high-resolution spectra, respectively. The high resolution scans were taken around 
the emission lines of interest with $0.1 \mathrm{eV}$ steps and $100 \mathrm{~ms}$ dwell time per point. SpecsLab Version 2.78 software was used for spectrometer control. The C 1s emission line of adventitious carbon (binding energy of $284.8 \mathrm{eV}$ ) was used to calibrate the energy scale of the spectra. The N1s peak was decomposed using the Casa XPS program (Casa Software Ltd) with a Gaussian/Lorentzian (70/30) product function and after subtraction of a Shirley background.

FTIR measurements of adsorbed pyrrole were carried out using a Thermo Nicolet Nexus 670 spectrometer equipped with a MCT detector. Spectra were acquired in the transmission mode, at a resolution of $4 \mathrm{~cm}^{-1}$ by averaging 250 scans. Samples were pressed into self-supporting wafers of ca. $3-7 \mathrm{mg} / \mathrm{cm}^{2}$ thickness and placed inside a glass cell provided with $\mathrm{KBr}$ windows and greaseless stopcocks. All sample manipulation was done inside a dry nitrogen-filled glove bag to prevent contact with oxygen and moisture. Samples were outgassed at $150{ }^{\circ} \mathrm{C}$ for $1 \mathrm{~h}$ (pressure less than $10^{-3}$ mbar), cooled down to $25^{\circ} \mathrm{C}$ and then pyrrole vapor (Aldrich, reagent grade, $98 \mathrm{wt} \%$ ) was dosed repeatedly to obtain increasing equilibrium pressures. The spectra have been normalized to a wafer thickness of $5 \mathrm{mg} / \mathrm{cm}^{2}$.

Catalysts were tested in the Michael addition reaction between chalcone and malononitrile as described elsewhere [10]. Michael addition reactions were carried out in batch mode using a round bottom flask equipped with a thermometer, a magnetic stirrer and a reflux condenser provided with a gas bubbler on the top connected to a nitrogen gas line. The bubbler valve was a glass bulb filled with silicone oil, designed in a way that allows to keep the reaction mixture under a constant ambient pressure of nitrogen and prevents the entry of ambient air in the reaction system in order to avoid the oxidation of the catalysts by water and oxygen. 
In a typical experiment, $833 \mathrm{mg}(4.0 \mathrm{mmol})$ of trans-chalcone ((2E)-1,3-diphenyl-2propen-1-one, Sigma-Aldrich, $97 \mathrm{wt} \%), 264 \mathrm{mg}$ (4.0 mmol) of malononitrile (cyanoacetonitrile, Sigma-Aldrich, $\geq 99 \mathrm{wt} \%$ ) and $150 \mathrm{mg}$ of anhydrous toluene (SigmaAldrich, $99.8 \mathrm{wt} \%$ ) as internal standard were dissolved in dry methanol (chalcone/methanol weight ratio of 0.05 ). An aliquot of this solution was taken to determine the composition of the reaction mixture at zero time before adding the solution over the catalyst (catalyst/chalcone weight ratio of 0.04 ), which was previously introduced in the round bottom flask inside a nitrogen-filled glove bag.

All the test reactions were performed at $60{ }^{\circ} \mathrm{C}$ under magnetic stirring and the progress of the reaction was monitored by withdrawing small aliquots $\left(0.1 \mathrm{~cm}^{3}\right)$ using a syringe at defined time intervals. The samples were diluted with $0.2 \mathrm{~cm}^{3}$ of chloroform, filtered and analyzed by gas chromatography using a Varian 430-GC gas chromatograph equipped with a flame ionization detector (FID) and a (95\%)-dimethyl-(5\%)diphenylpolysiloxane $\mathrm{DB}-5 \mathrm{~ms}$ capillary column $(15 \mathrm{~m} \times 0.25 \mathrm{~mm} \mathrm{ID} \times 0.25 \mu \mathrm{m})$. Under the same reaction conditions, a blank experiment (in the absence of catalyst) was performed resulting in a yield of $0 \%$ after $7 \mathrm{~h}$.

The product 2-(3-oxo-1,3-diphenylpropyl)malononitrile was isolated and identified by ${ }^{1} \mathrm{H}-\mathrm{NMR}$ spectroscopy as described elsewhere [10].

\section{Results and discussion}

Following the procedure described in the experimental section, several gels were prepared by the ammonolysis of mixtures of phosphoryl chloride and aluminum trichloride dissolved in the ionic liquid $\left[\mathrm{C}_{2} \mathrm{C}_{1} \mathrm{im}\right]\left[\mathrm{Tf}_{2} \mathrm{~N}\right]$, in the absence and also in the 
presence of several amounts of pyrrolidine. These gels were further heated at $180{ }^{\circ} \mathrm{C}$ under autogenous pressure for 2 or 4 weeks. Moreover, in separate portions of these gels, ammonia was dissolved under pressure prior the heating process. In this way, 12 different samples were prepared, according to the conditions described in Table 1.

\subsection{As-prepared samples}

ATR-FTIR spectra of the as-made samples prepared in the absence of pyrrolidine are shown in Fig. 1. In the wavenumber region $1500-600 \mathrm{~cm}^{-1}$, several bands corresponding to the $v_{\mathrm{a}}\left(\mathrm{SO}_{2}\right), v_{\mathrm{a}}\left(\mathrm{CF}_{3}\right), v(\mathrm{C}$-ethyl $), v_{\mathrm{s}}\left(\mathrm{SO}_{2}\right), v_{\mathrm{a}}(\mathrm{SNS}), v_{\mathrm{s}}(\mathrm{SNS}), v(\mathrm{CS})$ and $\gamma \mathrm{C}(\mathrm{i}) \mathrm{H}$ vibration modes characteristic of the fluorine- and sulphur-containing anion $\left[\mathrm{Tf}_{2} \mathrm{~N}\right]^{-}$of the ionic liquid are clearly visible in the spectra [14], indicating that the ionic liquid is retained by the samples, in spite of them having being abundantly washed with ethanol. It has been reported elsewhere that silicon diimide gels also retained substantial amounts of this ionic liquid after ethanol washing, which suggests that it would play an active role in forming the T-N network of these materials [9]. Moreover, an intense and asymmetric band is observed at $930 \mathrm{~cm}^{-1}$, which could be attributed to the antisymmetric stretching of P-N-T [15], where T could be either P or Al. The band at $1097 \mathrm{~cm}^{-1}$ also corresponds to a vibration mode of the T-N linkage. These two bands indicate the presence in the as-made material of a network formed by $\mathrm{T}-\mathrm{N}(\mathrm{T}=\mathrm{P}, \mathrm{Al})$ bonds. The heating of the samples under ammonia pressure does not have a major effect on the IR spectra.

The spectra of the samples in the $1800-1300 \mathrm{~cm}^{-1}$ region show the $\delta(\mathrm{NH})$ vibrational mode associated to three different chemical species. The bands at $1450 \mathrm{~cm}^{-1}, 1560 \mathrm{~cm}^{-1}$ and $1620 \mathrm{~cm}^{-1}$ correspond respectively to $\mathrm{NH}_{4}{ }^{+}$, terminal $-\mathrm{NH}_{2}$ groups associated to 
phosphorus [16] and ammonia, although the last band could also be contributed by water [11].

The spectra of the two sets of samples prepared in the presence of two different concentrations of pyrrolidine (Fig. 2) are qualitatively similar to those of the pyrrolidine-free samples just discussed, but a noticeable increase of the intensity of the $v(\mathrm{~T}-\mathrm{N})$ band at $1097 \mathrm{~cm}^{-1}$ is observed, as well as the splitting of the broad asymmetric band present in the pyrrolidine-free samples at nearly $930 \mathrm{~cm}^{-1}$ in two components at $911 \mathrm{~cm}^{-1}$ and $960 \mathrm{~cm}^{-1}$, the last one of lower intensity. In the region corresponding to the $\delta(\mathrm{NH})$ vibrational modes, it can be clearly observed that the heating of the gels under ammonia pressure strongly increased the amount of ammonium cations present in the samples, as well as the intensity of the band assigned to $-\mathrm{NH}_{2}$ terminal groups, the latter effect being more pronounced for the sample with the highest pyrrolidine content. It can be therefore concluded that the specific synthesis conditions would influence the polymerization degree of the $\mathrm{T}-\mathrm{N}$ network $(\mathrm{T}=\mathrm{P}, \mathrm{Al})$, which seems to decrease as the concentration of base molecules in the synthesis medium, namely pyrrolidine and ammonia, increases.

The chemical composition of the as-made samples is collected in Table 2. It can be observed that both $\mathrm{P}$ and $\mathrm{Al}$ are present in the samples, but their molar ratio changes as a function of the chemical composition and heating conditions of the synthesis gel. For those samples prepared in the absence of base molecules (pyrrolidine and ammonia), the $\mathrm{P} / \mathrm{Al}$ molar ratio is nearly 1.7 , but it drops to nearly one by heating the gel in the presence of ammonia. The same effect is observed by adding pyrrolidine instead of ammonia, with a decrease of the P/Al ratio to nearly 0.9 as the concentration of this base in the gel increases. The as-made material became even richer in aluminum $(\mathrm{P} / \mathrm{Al} \sim 0.7)$ 
by heating the pyrrolidine-containing gels in the presence of ammonia, i.e., in the presence of both compounds. Moreover, virtually in all cases the P/Al ratio decreases slightly by prolonging the heating time from 2 to 4 weeks. As equimolecular amount of $\mathrm{Al}$ and $\mathrm{P}$ are present in the initial reaction mixture, it can be concluded that these two compounds of base character, pyrrolidine and ammonia, promote the incorporation of aluminum in the material over that of phosphorus. Moreover, it can be also observed in the table that in spite of these variations of the relative content of $\mathrm{P}$ and $\mathrm{Al}$, the total amount of $\mathrm{P}+\mathrm{Al}$ in the samples remains in a narrow range of $28-33 \mathrm{wt} \%$. This behaviour would suggest the existence of a continuous $\mathrm{T}-\mathrm{N}-\mathrm{T}(\mathrm{T}=\mathrm{P}, \mathrm{Al})$ network whose relative content of $\mathrm{P}$ and $\mathrm{Al}$ is dictated by the gel chemistry and, in minor extension, also by the heating time.

These changes in the chemical composition are concomitant to some extension with those of the amount of ionic liquid trapped in the samples as determined mainly by carbon analysis. For the samples prepared in the absence of pyrolidine, the heating under ammonia pressure has little effect on the carbon content, and hence on the content of ionic liquid of the sample, as it is the only carbon source, which decreases as the heating time is prolonged. However, the addition of pyrrolidine led to a strong reduction of the total carbon content, which is further nearly halved by heating the reaction mixture under ammonia pressure for the gels richest in that base.

For the samples prepared in the absence of pyrrolidine and from the data gathered in Table 2, it can be concluded that the C/S molar ratio is much lower than that corresponding to the ionic liquid used in the synthesis. As sulphur is present only in the bis(trifluoromethylsulfonyl)imide anion, this suggests an excess of imidazolium cation that should be compensated by another anion present in the synthesis medium, which 
should be the chloride coming from the ammonolysis of the aluminum and phosphorus chlorides. For these samples prepared in the absence of pyrrolidine, it is possible to calculate the relative amount of $\left[\mathrm{C}_{2} \mathrm{C}_{1} \mathrm{im}\right]\left[\mathrm{Tf}_{2} \mathrm{~N}\right]$ and $\left[\mathrm{C}_{2} \mathrm{C}_{1} \mathrm{im}\right][\mathrm{Cl}]$ from the sulphur and carbon contents, and the results collected in Table 3 indicate the predominance of the chloride salt. It can be seen that the molar ratio of the organic species $\left(\left[\mathrm{C}_{2} \mathrm{C}_{1} \mathrm{im}\right]\left[\mathrm{Tf}_{2} \mathrm{~N}\right]\right.$ and $\left.\left[\mathrm{C}_{2} \mathrm{C}_{1} \mathrm{im}\right][\mathrm{Cl}]\right)$ to $(\mathrm{Al}+\mathrm{P})$, expressed as $\mathrm{Org} /(\mathrm{Al}+\mathrm{P})$ in Table 3 , decreases from 0.22 to 0.18 and 0.14 as a function of the synthesis time for gels synthesized in the absence and in the presence of ammonia pressure, respectively. For the samples synthesized in the presence of pyrrolidine, the chloride salt would be also probably the predominant, but as the relative amount of the pyrrolidine present in the solid has not been determined, this conclusion cannot be assessed.

Although the chemical analysis identifies the presence of nitrogen in the as-made samples, it has been shown before that the method used for its determination does not lead to reliable quantification of nitrogen [9].

Total weight loss of the pyrrolidine-free samples as determined by thermogravimetric analysis under air flow ranges from 36 to $48 \mathrm{wt} \%$ (see Table 3 and Fig.S1 of the Supporting information). Under these conditions, practically all volatile material is removed at $600^{\circ} \mathrm{C}$. Total weight loss decreases as pyrrolidine is added to the synthesis mixture, and the heating of these samples under ammonia pressure still lowered the total content of volatile compounds, an effect which is also produced by prolonging the heating time (Table 4). These variations in the weight loss patterns parallel those of the total carbon content discussed above.

\subsection{Ammonia-calcined samples}


Heating of the as-made samples in ammonia flow at $600{ }^{\circ} \mathrm{C}$ removes all the ionic liquid and also the pyrrolidine, if present, as only traces of $\mathrm{C}(<1 \mathrm{wt} \%)$ and $\mathrm{S}(<0.1 \mathrm{wt} \%)$ are found by chemical analysis of the ammonia-treated samples. Moreover, no bands corresponding to the different vibration modes of the ionic liquid can be detected in the FTIR spectra of these samples (Fig. 3). The most intense band in the spectra of the samples synthesized in the absence of pyrrolidine and ammonia appears at $1070 \mathrm{~cm}^{-1}$ and is assigned to a vibration mode of the T-N linkage, which is therefore shifted by $\sim 27 \mathrm{~cm}^{-1}$ to lower wavenumber as compared with the corresponding as-made samples. A shoulder of weak intensity is detected at $1220 \mathrm{~cm}^{-1}$. The $\mathrm{P}=\mathrm{O}$ stretching band appears at $1200-1350 \mathrm{~cm}^{-1}$, and the frequency of the band depends on the nature of the $\mathrm{P}$ substituents $[17,18]$. Therefore, the shoulder at $1220 \mathrm{~cm}^{-1}$ could be assigned to the $\mathrm{P}=\mathrm{O}$ stretching vibration. However, a band at $1209 \mathrm{~cm}^{-1}$ corresponding to a $\delta(\mathrm{NH})$ vibration mode has been detected in porous materials based on a $\mathrm{Si}-\mathrm{N}$ framework [9], so it should be considered that a $\delta(\mathrm{NH})$ vibration could also contribute to the shoulder at $1220 \mathrm{~cm}^{-1}$.

Another band at $697 \mathrm{~cm}^{-1}$ is clearly observed in the spectra of all ammonia-calcined samples, which could be assigned to the P-N stretching [18].

The presence of ammonia in the synthesis gel has a visible effect on the spectral features of the ammonia-calcined materials. The band at $1070 \mathrm{~cm}^{-1}$ is slightly shifted toward higher wavenumber $\left(1078 \mathrm{~cm}^{-1}\right)$ while the shoulder at $1220 \mathrm{~cm}^{-1}$ loses intensity. Moreover, two new bands at 1310 and $936 \mathrm{~cm}^{-1}$ develop. It has been reported that the frequency of the absorption band associated with the $\mathrm{P}=\mathrm{N}$ vibration appears in the region $1170-1438 \mathrm{~cm}^{-1}$ in cyclic compounds and other $\mathrm{P}$ compounds containing $\mathrm{N}=\mathrm{P}-\mathrm{N}$ bonds [16], which could eventually account for the band at $1310 \mathrm{~cm}^{-1}$. Indeed, the formation of $\mathrm{P}-\mathrm{N}=\mathrm{P}$ bonds in sodium nitride metaphosphate glasses has been 
demonstrated by ${ }^{15} \mathrm{~N}$ NMR [19]. The formation of $\mathrm{P}=\mathrm{N}$ bond would probably require the simultaneous formation of a P-O bond. Following this, the band at $936 \mathrm{~cm}^{-1}$ could be assigned to a stretching mode of the P-O group [18]. Nevertheless, the band at 936 $\mathrm{cm}^{-1}$ could also be attributed to the $\mathrm{P}-\mathrm{N}$ stretching vibration in the $\mathrm{P}-\mathrm{NH}_{2}$ group [16]. The spectra of the samples in the $1800-1300 \mathrm{~cm}^{-1}$ region are similar to those of the asmade samples, and a band at $1560 \mathrm{~cm}^{-1}$ corresponding to terminal $-\mathrm{NH}_{2}$ groups bonded to $\mathrm{P}$ is clearly visible in all the samples, whether synthesized in the presence or in the absence of ammonia. For this reason, it is most probable that the band at $936 \mathrm{~cm}^{-1}$ could be attributed to the P-N stretching vibration mode.

The addition of pyrrolidine to the synthesis gel does not modify substantially the spectra of the corresponding ammonia-calcined samples nor does the incorporation of ammonia to the synthesis gel, although the most intense band shifts to $1086 \mathrm{~cm}^{-1}$ in the latter case, while the band at $936 \mathrm{~cm}^{-1}$ shifts to $\sim 950 \mathrm{~cm}^{-1}$ (Fig.S2 of the Supporting information). These changes in the FTIR spectra suggest modifications in the overall composition of the $\mathrm{T}-\mathrm{N}(\mathrm{T}=\mathrm{P}, \mathrm{Al})$ network, in consistence with the observed changes in the chemical composition, and eventually also in the bonding scheme of the $\mathrm{T}$ to $\mathrm{N}$ atoms of the solid in response to specific synthesis conditions. For instance, the band at $936-950 \mathrm{~cm}^{-1}$ is clearly observed only when the synthesis gel is heated in ammonia atmosphere, which suggests higher amount of terminal $\mathrm{P}-\mathrm{NH}_{2}$ groups in these samples. It is also interesting to notice that the frequency of the bands associated to $v(\mathrm{~T}-\mathrm{N})$ vibration modes are clearly influenced by the chemical composition of the framework. Compared to Si-N sample [9], the two bands appearing in the ranges $1000-1100 \mathrm{~cm}^{-1}$ and $900-950 \mathrm{~cm}^{-1}$ are shifted to higher wavenumber for $\mathrm{P}$ and $\mathrm{Al}$ containing materials, while their relative intensities are also modified. 
Removal of the ionic liquid by heating in ammonia flow led to materials with high surface area and porosity (Table 5). Most of the surface area and pore volume correspond to mesopores, with very little presence of microporosity. However, the textural properties are affected by the specific synthesis conditions according to a complex pattern that will be described as follows. For the samples synthesized in the absence of ammonia, when no pyrrolidine is used the surface area is about $110 \mathrm{~m}^{2} \cdot \mathrm{g}^{-1}$, total pore volume $0.6 \mathrm{~cm}^{3} \cdot \mathrm{g}^{-1}$ and the average pore size nearly $20 \mathrm{~nm}$. The addition of pyrrolidine to the gel increases the surface area to $\sim 150 \mathrm{~m}^{2} \cdot \mathrm{g}^{-1}$, but reduces the pore volume and shrinks the average diameter of pores down to $9 \mathrm{~nm}$ for the samples prepared with the highest concentration of base.

By adding ammonia to the synthesis gel in the absence of pyrrolidine, the surface area nearly duplicates up to $229 \mathrm{~m}^{2} \cdot \mathrm{g}^{-1}$, while pore volume raises to $1.06 \mathrm{~cm}^{3} \cdot \mathrm{g}^{-1}$, and pore size slightly decreases to $17 \mathrm{~nm}$. However, for the samples containing pyrrolidine, the opposite effect is produced by ammonia, both surface area and pore volume decrease, while the average pore size is slightly enlarged. This effect is much more pronounced for the gel richest in pyrolidine, for in this case the surface area drops to $46 \mathrm{~m}^{2} \cdot \mathrm{g}^{-1}$ and the pore volume to $0.17 \mathrm{~cm}^{3} \cdot \mathrm{g}^{-1}$. The overall variation trends of textural properties as a function of synthesis conditions are not essentially modified by increasing the synthesis time from 14 days to 28 days, although some minor effect are observed in some cases.

As it can be seen in Fig. 4, there is a trend for the pore volume to correlate positively with the TG weight loss.

As it can be seen in Table 3 and TG analyses (Fig. S1 of the Supporting information), most of the weight loss is contributed by the ionic liquid [9], although some other 
chemical species would be responsible for the weight loss found at lower temperature. In any case, this correlation evidences the pore-forming role of the ionic liquid.

${ }^{31}$ P MAS NMR spectra of some selected ammonia-calcined samples are presented in Fig. 5, while the corresponding ${ }^{27} \mathrm{Al}$ MAS NMR spectra are shown in Fig. 6.

In the ${ }^{31} \mathrm{P}$ spectra, a very broad asymmetric band is observed in the range $-40 \mathrm{ppm}$ to 20 ppm, whose shape and center of gravity change as a function of the synthesis conditions. For the sample synthesized in the absence of pyrrolidine, the broad band is centered at about $-15 \mathrm{ppm}$. This band is the result of the overlapping of several individual signals. The treatment of $\mathrm{NaPO}_{3}$ glasses with ammonia led to the formation of PON glasses. For this material, ${ }^{31} \mathrm{P}$ NMR resonances at $-10 \mathrm{ppm}$ and $0 \mathrm{ppm}$ have been assigned to $\mathrm{PO}_{3} \mathrm{~N}$ and $\mathrm{PO}_{2} \mathrm{~N}_{2}$ local bonding configurations, respectively [19]. The same signals have been observed in LiNaPON glasses, corresponding to $\mathrm{P}$ atoms in $\mathrm{Q}^{2}$ configuration, where the signal of the parent glass appears at $-21.4 \mathrm{ppm}$ [20]. Therefore, replacing $\mathrm{O}$ by $\mathrm{N}$ produces an increase of the ${ }^{31} \mathrm{P}$ chemical shift, which is also influenced by the condensation degree. In phosphorus oxonitridosodalites with a tridimensional framework formed by corner-sharing $\mathrm{PN}_{3} \mathrm{O}$ tetrahedra, the ${ }^{31} \mathrm{P}$ MAS NMR spectrum exhibits one signal at $\delta=-8.7 \mathrm{ppm}$ [21]. In the case of phosphoryl triamide polymers containing the $\mathrm{P}=\mathrm{O}$ group, up to three types of non-equivalent phosphorus nuclei in the polymer units have been reported. The signal at the highest field $(-31.9 \mathrm{ppm})$ corresponds to the end group of the chain polymer $-\mathrm{NH}-\mathrm{PO}(\mathrm{NH})_{2}$; the one at -18.2 ppm to the linear unit - $\mathrm{NH}-\mathrm{PO}\left(\mathrm{NH}_{2}\right)-\mathrm{NH}-$, and the most deshielded one at $10.1 \mathrm{ppm}$ is attributed to the branching unit $-\mathrm{NH}-\mathrm{PO}(-\mathrm{NH}-)_{2}$ [22]. The chemical shift of these resonance signals corresponding to $\mathrm{P}$ atoms bonded at least to one $\mathrm{O}$ atom and to $\mathrm{N}$ atoms according to different bonding schemes, are in the wide chemical shift range of 
the samples presented in Fig. 5, and furthermore are consistent with the information gathered from the FTIR spectra discussed above concerning the presence of terminal $\mathrm{P}-\mathrm{NH}_{2}$ groups and T-N-T bonds. The broadening of the signals points to a complex nature of the P-N-P network, built with the contribution of a variety of chemical environments of $\mathrm{P}$ atoms, whose relative importance would be affected by specific synthesis conditions, as it can be deduced from the differences observed in the shape of the broad resonance signal. For instance, the spectrum of the sample synthesized in the absence of pyrrolidine but under ammonia pressure, AlP-OPy-28d-NH, shows the highest intensity at $\sim-10 \mathrm{ppm}$, while this occurs at $\sim-23 \mathrm{ppm}$ for the sample AlP-2Py$14 \mathrm{~d}$, synthesized without ammonia but in the presence of pyrrolidine.

The ${ }^{27}$ Al MAS NMR spectra of the samples consist of up to three broad signals at $~ 35$ ppm, $12 \mathrm{ppm}$ and - $10 \mathrm{ppm}$, whose relative intensity changes for the different samples. While the one at lower field dominates the spectrum of the sample synthesized in the presence of ammonia, and that at $\sim 12 \mathrm{ppm}$ is hardly observed as a shoulder on the first one, if pyrrolidine but no ammonia is present in the gel, then the intensity of the high field signal is nearly the same as that observed at $35 \mathrm{ppm}$, and the one at $\sim 12 \mathrm{ppm}$ is clearly observed. The replacement of oxygen by nitrogen in the first coordination shell of $\mathrm{Al}$ atoms would result in higher chemical shift values. The ${ }^{27} \mathrm{Al}$ chemical shift for $\mathrm{AlO}_{3} \mathrm{~N}$ is $75 \mathrm{ppm}$, and $89 \mathrm{ppm}$ for $\mathrm{AlO}_{2} \mathrm{~N}_{2}$ in $\mathrm{SiAlON}$ ceramics [23]. However, no signals in that region of chemical shift values are observed in Fig. 6 and, therefore, no Al-N bonds would be present in these materials. A similar conclusion has been reported for the $\mathrm{N}$-containing materials resulting from the treatment of amorphous aluminophosphates with ammonia at high temperature [24]. The peak at $35 \mathrm{ppm}$ can be assigned to tetrahedral aluminum coordinated to oxygen atoms, while those at higher field would correspond to aluminum atoms coordinated additionally to one and two 
ammonia molecules [24]. Following this assignment, the aluminum atoms would be coordinated by the oxygen atoms of $\mathrm{P}_{-}^{-} \mathrm{O}^{-}$groups, where the $\mathrm{P}$ atoms would be involved in $\mathrm{P}=\mathrm{N}$ bonds, which are indeed detected by FTIR, as discussed above. In this coordination scheme, the $\mathrm{Al}$ atoms would play a role as cross-linkers of the P-N-P groups leading in this way to a tridimensional network. If this is so, if no Al-N bonds are present in the samples, it would mean that the base properties of the $\mathrm{N}$ atoms attached to $\mathrm{P}$ would not be essentially affected by the presence of aluminum in the material.

Binding energy values of $\mathrm{Al} 2 \mathrm{p}, \mathrm{P} 2 \mathrm{p}, \mathrm{O} 1 \mathrm{~s}$ and $\mathrm{N}$ 1s core-levels determined by X-ray photoelectron spectroscopy for some selected samples are collected in Tables 6 and 7.

The peaks corresponding to $\mathrm{Al}, \mathrm{P}$ and $\mathrm{O}$ are quite symmetric. The binding energy of $\mathrm{Al}$ $2 \mathrm{p}$ is $74.5 \mathrm{eV}$, the same value reported for this element in amorphous aluminophosphate [8], and it indicates that aluminum is bonded to oxygen atoms in the samples, in agreement with the ${ }^{27} \mathrm{Al}$ MAS NMR results discussed above. Fig. 7 shows the $\mathrm{N} 1 \mathrm{~s}$ core-level spectra of the samples listed in Table 7. The signal is broad and asymmetric, and shoulders are clearly identified at both lower and higher binding energy than the main peak detected at $\sim 399 \mathrm{eV}$. The spectra can be decomposed into three components, located at $397.2 \pm 0.3 \mathrm{eV}, 399 \pm 0.3 \mathrm{eV}$ and $401 \pm 0.2 \mathrm{eV}$. The two peaks at lower binding energy have also been commonly detected in phosphorus oxynitride glasses, and can be assigned to nitrogen atoms coordinated to two $\mathrm{P}$ atoms in $-\mathrm{N}=$ configurations, and to $\mathrm{N}$ atoms which are linked to three $\mathrm{P}$ atoms $(>\mathrm{N}-)$, respectively [25]. These signals have also been observed in $\mathrm{P}_{5} \mathrm{~N}_{5} \mathrm{H}_{\mathrm{x}}$ compounds [26], and the observed $1.8 \mathrm{eV}$ energy difference between the two peaks is consistent though slightly 
higher than the 1.5-1.6 eV reported in [26]. However, the peak at $399 \mathrm{eV}$ could be also contributed by imidophosphate species containing protonated nitrogen, P-NH-P [27-29].

Indeed, protonated -NH- groups have been identified by IR spectroscopy in aluminophosphate oxynitrides [5].

Regarding the assignment of the $401 \mathrm{eV}$ peak, an intense peak at $401.8 \mathrm{eV}$ has been observed for hydrogen-rich PONH glasses prepared by decomposing $\mathrm{NH}_{4} \mathrm{H}_{2} \mathrm{PO}_{4}$ in ammonia at $720{ }^{\circ} \mathrm{C}$ [28] and it has been attributed to nitrogen present in terminal $\mathrm{P}-\mathrm{NH}_{2}$. Similar assignment has been done for oxynitride surface layers on sodium and lithium metaphosphate glasses [29]. The relative contribution of each component to the $\mathrm{N} 1 \mathrm{~s}$ spectra is collected in Table 7. It can be seen that most of the nitrogen atoms are tricoordinated, as they account for 63 to $77 \%$ of the total. In contrast, there is a large variability in the relative contribution of the double-bonded and terminal $\mathrm{N}$ atoms. The contribution of $\mathrm{P}-\mathrm{NH}_{2}$ groups ranges from 5 to $28 \%$, and that of dicoordinated $\mathrm{N}$ from 4 to $31 \%$. Moreover, the fraction of terminal $\mathrm{P}-\mathrm{NH}_{2}$ seems to increase with the surface area of the samples (Fig. 8). Two different regions can be identified in the plot of surface area vs. fraction of $\mathrm{P}-\mathrm{NH}_{2}$ groups. Below $\sim 100 \mathrm{~m}^{2} \cdot \mathrm{g}^{-1}$, the fraction of $\mathrm{P}-\mathrm{NH}_{2}$ groups increases rapidly with surface area, while beyond this point there is a large increase of terminal groups for a relatively small increment of surface area. This behavior suggests that for samples with surface area $>\sim 100 \mathrm{~m}^{2} \cdot \mathrm{g}^{-1}$ an increasingly larger fraction of terminal $\mathrm{P}-\mathrm{NH}_{2}$ groups would be internal, non-exposed to the surface. Nevertheless, these groups would still be accessible to the XPS measurement.

In the $\mathrm{O} 1 \mathrm{~s}$ spectra only one symmetric peak centered at $531.9 \mathrm{eV}$ is observed (Fig. S3 of the Supplementary Information). This peak has been assigned to non-bridging oxygen atoms linked to $\mathrm{P}$ atoms in the $\mathrm{P}=\mathrm{O}$ group [28] although Marchand et al. [25] 
separate this peak in two close components corresponding to $\mathrm{P}=\mathrm{O}$ and $\mathrm{P}_{-}^{-} \mathrm{O}^{-}$species. This assignment is consistent with the ${ }^{31} \mathrm{P}$ and ${ }^{27} \mathrm{Al}$ MAS NMR spectra discussed above. It also suggests that at least a portion of the $\mathrm{P}=\mathrm{O}$ groups of the phosphoryl chloride used as reagent survive during the preparation of gel and subsequent heating at high temperature in ammonia. It is also interesting to notice the absence of a peak at $\sim 534$ $\mathrm{eV}$, which has been attributed to oxygen atoms bridging two $\mathrm{P}$ atoms in $\mathrm{P}-\mathrm{O}-\mathrm{P}$ configuration $[25,28,29]$. Therefore, the network of the material is formed by nitrogen atoms bonded to phosphorus, which also bear terminal oxygen atoms.

The P 2p spectra (not shown) show a symmetric signal centered at 133.4-133.8 eV, which is consistent with the presence of $\mathrm{P}$ atoms linked to $\mathrm{N}$ and some $\mathrm{O}$ atoms [11, 27]. The chemical composition of the surface as determined by XPS is collected in Table 6. It can be seen that the surface P/Al ratios are the same as those of the bulk for the samples prepared in the absence of pyrrolidine, whereas the surface is enriched in aluminum for those prepared in the presence of this organic base. The N/P ratio is in the range $0.8-0.9$ save for one sample, while the $\mathrm{O} /(\mathrm{P}+\mathrm{Al})$ ratio is $1.5-1.9$. Overall, the $(\mathrm{N}+\mathrm{O}) /(\mathrm{P}+\mathrm{Al})$ is 2.1 . These results show an excess of oxygen atoms, which might result from the partial oxidation and/or hydrolysis of the surface of the sample as it was transferred to the XPS instrument. However, this oxidation would result in the formation of additional P-O terminal groups from P-N linkages, as no P-O-P bonds are detected.

FTIR spectra of selected AIPON samples submitted to thermal treatment under ammonia were recorded after degassing at $150{ }^{\circ} \mathrm{C}$ and in contact with pyrrole vapor. Fig. 9 shows these spectra in the $3700-3300 \mathrm{~cm}^{-1}$ wavenumber range, corresponding to absorption bands of $\mathrm{O}-\mathrm{H}$ and $\mathrm{N}-\mathrm{H}$ stretching modes. In this region, the spectra of pre- 
treated samples show a strong band, which maximum appears at $3335-3350 \mathrm{~cm}^{-1}$, and two medium to weak shoulders at 3455 and $3290 \mathrm{~cm}^{-1}$. Based on the chemical composition determined by the XPS analyses discussed above and on previously reported FTIR spectroscopy characterization of nitrided aluminophosphates $[5,6,8]$, the most intense band can be assigned to the $\mathrm{N}-\mathrm{H}$ stretching of $\mathrm{P}-\mathrm{NH}-\mathrm{P}(\mathrm{Al})$ groups, while the shoulders at 3455 and $3290 \mathrm{~cm}^{-1}$ might correspond to the asymmetric and symmetric $\mathrm{H}-\mathrm{N}-\mathrm{H}$ stretching modes of $\mathrm{P}-\mathrm{NH}_{2}$ groups, respectively. It can be observed in Fig. 9 that the relative intensities of the bands at $3455 \mathrm{~cm}^{-1}$ (assigned to terminal $-\mathrm{NH}_{2}$ ) and 3350 $\mathrm{cm}^{-1}$ (assigned to bridging -NH-) are similar for all the analyzed samples, although the spectrum of sample AlP-0Py-28d-NH shows clearly a slightly higher proportion of terminal $-\mathrm{NH}_{2}$ groups, in agreement with XPS results that show for this sample higher ratio of the N1s component at $401 \mathrm{eV}$ respect to the component at $399 \mathrm{eV}$.

The FTIR spectra also show a weak broad band around $3600 \mathrm{~cm}^{-1}$ with a very weak shoulder at $3678 \mathrm{~cm}^{-1}$ that can be assigned to interacting and isolated $\mathrm{P}-\mathrm{OH}$ groups, respectively [5]. This result indicates that the samples might have undergone some degree of oxidation. However, the weak intensity of these later bands evidences that the extent of surface oxidation in these samples is very low.

FTIR spectra recorded after adsorption of pyrrole (Fig. 9) show an increase of absorption in the region of $\mathrm{N}-\mathrm{H}$ stretching bands due to the overlapping of the $\mathrm{v}(\mathrm{NH})$ band of adsorbed pyrrole. In order to determine the actual location of this band, difference spectra were obtained by subtracting to these spectra the one corresponding to the respective degassed sample. The difference spectra obtained at low equilibrium pressure of pyrrole show a single band centered at ca. $3440 \mathrm{~cm}^{-1}$, which can be attributed to the $\mathrm{N}-\mathrm{H}$ stretching of pyrrole adsorbed on basic sites, while at higher 
equilibrium pressure an additional band appears at $3410 \mathrm{~cm}^{-1}$, which can be assigned to physisorbed pyrrole [30]. It can be seen that, for all the samples, the adsorption of pyrrole on basis sites produces a similar shift of its N-H stretching band (ca. $90 \mathrm{~cm}^{-1}$ ) respect to the band position found for free pyrrole molecules in the vapor phase (3530 $\left.\mathrm{cm}^{-1}[10]\right)$. This shift of the $v(\mathrm{NH})$ band of pyrrole due to interaction with electron donor sites has been considered as a measure of the relative strength of basic sites [30]. Therefore, the calculated shifts (Table 8) indicate that the three samples exhibit similar basic strength. By comparing the magnitud of this shift with results obtained for other solid basic materials, it can be concluded that these AlPON samples exhibit higher basic strength than $(\mathrm{Si}, \mathrm{Al})-\mathrm{N}$ materials synthesized by a similar route, but lower basic strength than a strongly basic mixed oxide obtained by calcination of an $\mathrm{Al}-\mathrm{Mg}$ hydrotalcite [10].

The basic properties of the samples are due to the nitrogen atoms linked to phosphorus. In this regard, the XPS results show the presence of several types of $\mathrm{N}$ atoms, namely one $\mathrm{N}$ bonded to three $\mathrm{P}$ atoms, eventually a bridging $\mathrm{NH}$ group bonded to two $\mathrm{P}$ atoms, $\mathrm{N}$ attached to two different $\mathrm{P}$ atoms forming one double and one single bond, respectively, and finally terminal $\mathrm{P}-\mathrm{NH}_{2}$ groups. Therefore, the overall basic strength determined by pyrrole adsorption would be an average of the chemical interaction of this molecule with the nitrogen atoms present in these different chemical environments. On this matter, it has been argued that the basic strength of bridging -NH- species would be higher than that of terminal $-\mathrm{NH}_{2}[5]$ which would also be in agreement with results reported for pyrrole adsorption on $(\mathrm{Si}, \mathrm{Al})-\mathrm{N}$ materials synthesized in ionic liquids [10]. While this conclusion might probably also hold for the AlPON materials described here, it cannot be proven in a conclusive manner owing to the fact that the 
relative proportion of the different $\mathrm{N}$ environments for the three tested samples is quite similar (Table 7).

\subsection{Catalytic activity}

The activity of some selected samples has been determined in the Michael addition reaction between chalcone and malononitrile. The yield to the only reaction product detected, the 1,4-addition compound, has been plotted in Fig. 10 as a function of the reaction time. It can be seen in the figure that the yield increases rapidly up to nearly 1 $\mathrm{h}$, but it increases much more slowly as the reaction is prolonged beyond $2 \mathrm{~h}$. At this reaction time, $2 \mathrm{~h}$, the yield of the most active sample raises to nearly $60 \%$. It can be noticed that the sample with the lowest activity is the one possessing the smaller surface area (see Table 5). This observation suggests that there would be a relationship between surface area and activity, and this is indeed observed when the yield at 30 minutes of reaction time is plotted as a function of surface area (Fig. 11). As a consequence of this virtually lineal increase of yield with surface area, the activity per unit surface area is quite similar for the samples tested (Table 9). This finding would mean that the density and strength of the basic active sites present at the surface of the catalysts would be hardly affected by the synthesis procedure. Indeed, the results of pyrrole adsorption discussed above already evidenced that the strength of the basic sites present in the samples is nearly the same, as it is so the surface N/P ratio (Table 6).

The activity of the phosphorus-based samples can be compared with that reported for pure silicon-nitrogen materials synthesized by the same experimental procedure [10]. At the same reaction time, 15 minutes, the yield of the P-N materials per unit surface area is nearly four times that of $\mathrm{Si}-\mathrm{N}$ catalysts. This enhancement of the catalytic activity is 
in agreement with the higher basicity of the P-N materials as determined by pyrrole adsorption. The Michael addition reaction takes place by the abstraction of a proton from an acidic group, in this case the methylene group of malononitrile (Michael donor), in such a way that the resultant carbanion is added to the carbon double bond attached to the phenyl group of the chalcone (Michael acceptor). Therefore, the strength of the basic sites of the catalysts is at least enough to deprotonate the active methylene group of the malononitrile, which has $\mathrm{pK}_{\mathrm{a}}=11$.

AlPON materials prepared by nitridation of amorphous aluminophosphate with ammonia at high temperature have been shown to be active in the Knoevenagel condensation reaction between malononitrile and benzaldehyde [3-6] or acetophenone [31] and all these works report $100 \%$ selectivity to the condensation product, and in particular no products resulting from the Michael addition to the product containing a double bond resulting from the Knoevenagel reaction have ever been found. In all of these reports, the absence of Michael addition products is attributed by the respective authors to the more demanding character of this reaction as compared with Knoevenagel condensation, which would require stronger basic sites to occur. However, it is clearly shown in this work that the AlPON materials synthesized in ionic liquids do catalyze the Michael addition reaction between malononitrile and chalcone. It would be tempting to attribute this unprecedented activity to the presence of some particularly active basic sites that would be formed by this novel synthesis route. On this regard, it can be noticed that the presence of terminal $-\mathrm{NH}_{2}$ and bridging $-\mathrm{NH}$ - groups have been reported in the catalysts used by Climent et al [5]. The broad $\mathrm{N} 1 \mathrm{~s}$ signal observed in the XPS spectra of the materials described by Massinon et al [4] would be consistent with the presence of di- and tricoordinated $\mathrm{N}$ atoms, whereas very few terminal groups would be present. However, no attempt was made in that work to identify the several 
components of the spectra. This was done by Benitez et al [8] but only two components in the $\mathrm{N}$ 1s spectra were identified, the one at binding energy $398.9 \mathrm{eV}$ attributed to terminal $-\mathrm{NH}_{2}$ groups and that at $397.5 \mathrm{eV}$ assigned to "structural" nitrogen in $-\mathrm{NH}-$, $>\mathrm{N}$ - and $=\mathrm{N}$ - configurations. In spite of the shortcomings of some of these assignments, the characterization results of AIPON materials prepared in this work and discussed in previous paragraphs do not reveal the presence of nitrogen environments which would be fundamentally different to those observed before in N-containing aluminophosphate materials prepared by ammonia treatment of amorphous precursors at high temperature, save might be the presence in our case of much higher concentration of terminal $\mathrm{P}-\mathrm{NH}_{2}$ groups. Although additional research should be done to determine the relative basic strength of the several chemical environments of nitrogen atoms present in conventional AlPON prepared from amorphous precursors, in order to determine whether they are identical to those existing in the materials synthesized by the procedure described in this work, there would be another plausible explanation for the lack of activity in the Michael reaction of the former. When the catalysts are tested in Knoevenagel condensation, water is formed, and it could eventually poison the strongest basic groups initially present in the pristine catalysts, which would not be able in this way to catalyse further the demanding Michael addition.

At any rate, in the light of the available experimental evidences, it would be convenient to reconsider the statements on the basic strength of AlPON as not being sufficient to carry out the Michael addition [13]. 


\section{Conclusions.}

ALPON materials with high surface area and porosity have been successfully synthesized by ammonolysis of molecular precursors at low temperature in ionic liquids. Several characterization techniques confirm the existence of a network formed by phosphorus-to-nitrogen bonds, where the $\mathrm{P}$ atoms are linked to oxygen atoms as well, which was already present in the phosphoryl chloride used as P source. These oxygen atoms coordinate the aluminum atoms present in the solid, which would behave as cross linkers of the whole P-N network. No evidences have been found on the existence of Al-N bonds. XPS clearly show the presence of $\mathrm{N}$ atoms in several coordination schemes, involving the formation of $\mathrm{P}=\mathrm{N}$ double bond, $\mathrm{P}-\mathrm{N}$ single bonds where the nitrogen atom could be linked either to three or two $\mathrm{P}$ atoms, in the latter case the nitrogen atom would be linked in addition to an hydrogen atom and, finally, terminal $\mathrm{P}-\mathrm{NH}_{2}$ groups. The overall strength of the basic sites present in the samples, evidenced by pyrrole adsorption, is higher than that of silicon-nitrogen compounds prepared by the same synthesis procedure, yet lower than that of a calcined $\mathrm{Al}-\mathrm{Mg}$ hydrotalcite. Nevertheless, it has been clearly shown that these materials are quite active catalysts for the demanding Michael addition reaction between the donor malononitrile and the acceptor chalcone, where only the addition product is formed.

\section{Acknowledgments}

The authors gratefully acknowledge the Spanish Ministry of Economy and Competitiveness for the funding through Projects MAT2013-31127 and MAT201677496-R. A. Saugar also acknowledges support from the CSIC Jae-Predoc program cofinanced by the European Social Fund. 
Journal of Catalysis, 348 (2017) 177-188

\section{References}

[1] R. Marchand, J. Non-Cryst. Solids 56 (1983) 173.

[2] R. Marchand, C. R. Acad. Sci. Ser. II 294 (1982) 91.

[3] P. Grange, P. Bastians, R. Conanec, R. Marchand, Y. Laurent, Appl. Catal. A 114 (1994) L191.

[4] A. Massinon, J.A. Odriozola, P. Bastians, R. Conanec, R. Marchand, Y. Laurent, P. Grange, Appl. Catal. A 137 (1996) 9.

[5] M.J. Climent, A. Corma, V. Fornés, A. Frau, R. Guil-López, S. Iborra, J. Primo, J. Catal. 163 (1996) 392.

[6] J. Wang, Q. Liu, J. Mater. Res. 22 (2007) 3330.

[7] A. Stein, B. Wehrle, M. Jansen, Zeolites 13 (1993) 291.

[8] J. J. Benitez, A. Diaz, Y. Laurent, J. A. Odriozola, J. Mater. Chem. 8 (1998) 687.

[9] A.I. Saugar, A. Mayoral, J. Pérez-Pariente, Microporous Mesoporous Mater. 186 (2014) 146.

[10] A.I. Saugar, C. Márquez-Álvarez, I.J. Villar-Garcia, T. Welton, J. Pérez-Pariente, Appl. Catal. A 520 (2016) 157.

[11] J. Benitez, A. Diaz, Y. Laurent, J. Odriozola, Appl. Catal. A 176 (1999) 177.

[12] H. Hattori, Chem. Rev. 95 (1995) 537.

[13] Y. Ono, H. Hattori, Solid Base Catalysis, Springer, 2011, p. 11.

[14] O. Höfft, S. Bahr, V. Kempter, Langmuir 24 (2008) 11562.

[15] A.B. Burg, J. Heners, J. Am. Chem. Soc. 87 (1965) 3092.

[16] R.A. Chittenden, L. Thomas, Spectrochim. Acta 22 (1966) 1449.

[17] L. Bellamy, L. Beecher, J. Chem. Soc. (1952) 475.

[18] D. Corbridge, E. Lowe, J. Chem. Soc. (1954) 493.

[19] B.C. Bunker, D.R. Tallant, C.A. Balfe, R.J. Kirkpatrick, G.L. Turner, M.R. Reidmeyer, J. Am. Ceram. Soc. 70 (1987) 675. 
[20] A. Le Sauze, L. Montagne, G. Palavit, F. Fayon, R. Marchand, J. Non-Cryst. Solids 263 (2000) 139.

[21] N. Stock, E. Irran, W. Schnick, Chem. Eur. J. 4 (1998) 1822.

[22] R. Pietschnig, M. Fechtelkord, S. Spirk, G.N. Rechberger, J. Inorg. Organomet. Polym. Mater. 18 (2008) 272.

[23] M.E. Smith, J. Phys. Chem. 96 (1992) 1444.

[24] T. Blasco, A. Corma, L. Fernández, V. Forne, R. Guil-López, Phys. Chem. Chem. Phys. 1 (1999) 4493.

[25] R. Marchand, D. Agliz, L. Boukbir, A. Quemerais, J. Non-Cryst. Solids 103 (1988) 35.

[26] S. Vepřek, Z. Iqbal, J. Brunner, M. Schärli, Philos. Mag. B 43 (1981) 527.

[27] R.K. Brow, M.R. Reidmeyer, D.E. Day, J. Non-Cryst. Solids 99 (1988) 178.

[28] R.K. Brow, Y.B. Peng, D.E. Day, J. Non-Cryst. Solids 126 (1990) 231.

[29] E.-T. Kang, D.E. Day, J. Non-Cryst. Solids 126 (1990) 141.

[30] B. Camarota, Y. Goto, S. Inagaki, B. Onida, Langmuir 27 (2011) 1181.

[31] M. Climent, A. Corma, R. Guil-Lopez, S. Iborra, Catal. Lett. 74 (2001) 161. 


\section{TABLES}

Table 1. Phosphorus-aluminum oxyimide samples prepared from gels with the following molar composition: $1 \mathrm{OPCl}_{3}: 1 \mathrm{AlCl}_{3}: x \mathrm{Py}: 2.8\left[\mathrm{C}_{2} \mathrm{C}_{1} \mathrm{im}\right]\left[\mathrm{Tf}_{2} \mathrm{~N}\right]:$ y $\mathrm{NH}_{3}$, where Py stands for Pyrrolidine and $y$ stands for the quantity of ammonia dissolved in the gel before the heating process. All the gels were heated statically at $180{ }^{\circ} \mathrm{C}$.

\begin{tabular}{llll}
\hline Sample & $x$ & $y$ & $t^{a}$ (days) \\
\hline AlP-0Py-14d & 0 & 0 & 14 \\
AlP-0Py-28d & 0 & 0 & 28 \\
AlP-0Py-14d-NH & 0 & 5.5 & 14 \\
AlP-0Py-28d-NH & 0 & 5.5 & 28 \\
AlP-1Py-14d & 1 & 0 & 14 \\
AlP-1Py-28d & 1 & 0 & 28 \\
AlP-1Py-14d-NH & 1 & 5.5 & 14 \\
AlP-1Py-28d-NH & 1 & 5.5 & 28 \\
AlP-2Py-14d & 2 & 0 & 14 \\
AlP-2Py-28d & 2 & 0 & 28 \\
AlP-2Py-14d-NH & 2 & 5.5 & 14 \\
AlP-2Py-28d-NH & 2 & 5.5 & 28 \\
\hline & & & \\
\hline
\end{tabular}

${ }^{\mathrm{a}}$ Heating time. 
Table 2. Elemental composition of the as-prepared samples determined by CHNS chemical analysis and ICP-OES (P and Al).

\begin{tabular}{|c|c|c|c|c|c|c|c|}
\hline \multirow[b]{2}{*}{ As-prepared sample } & \multicolumn{4}{|c|}{ Chemical CHNS analysis } & \multicolumn{3}{|c|}{$I C P-O E S$} \\
\hline & $\begin{array}{l}C \\
(w t \%)\end{array}$ & $\begin{array}{l}H \\
(w t \%)\end{array}$ & $\begin{array}{l}N \\
(w t \%)\end{array}$ & $\begin{array}{l}S \\
(w t \%)\end{array}$ & $\begin{array}{l}P \\
(w t \%)\end{array}$ & $\begin{array}{l}A l \\
(w t \%)\end{array}$ & $P / A l^{a}$ \\
\hline AlP-0Py-14d & 15.21 & 5.82 & 9.33 & 1.16 & 18.91 & 9.21 & 1.78 \\
\hline AlP-0Py-28d & 13.6 & 5.39 & 9.12 & 0.78 & 19.79 & 10.06 & 1.71 \\
\hline AlP-0Py-14d-NH & 16.08 & 5.98 & 7.85 & 0.76 & 15.26 & 13.33 & 0.99 \\
\hline AlP-0Py-28d-NH & 11.99 & 4.71 & 10.42 & 1.12 & 17.53 & 16.00 & 0.95 \\
\hline AlP-1Py-14d & 7.52 & 3.24 & 4.04 & 1.05 & 18.0 & 14.7 & 1.06 \\
\hline AlP-1Py-28d & 6.92 & 3.05 & 2.81 & 1.16 & 17.2 & 15.8 & 0.95 \\
\hline AlP-1Py-14d-NH & 4.67 & 3.27 & 12.3 & 0.62 & 14.9 & 16.6 & 0.78 \\
\hline AlP-1Py-28d-NH & 5.25 & 3.29 & 11.42 & 0.87 & 14.7 & 16.9 & 0.76 \\
\hline AlP-2Py-14d & 10.00 & 3.95 & 5.23 & 1.24 & 16.0 & 15.3 & 0.91 \\
\hline AlP-2Py-28d & 8.69 & 3.54 & 4.63 & 1.25 & 15.6 & 15.9 & 0.85 \\
\hline AlP-2Py-14d-NH & 4.28 & 3.48 & 14.62 & 0.74 & 13.3 & 17.5 & 0.66 \\
\hline AlP-2Py-28d-NH & 3.97 & 3.42 & 13.42 & 0.69 & 14.8 & 16.7 & 0.77 \\
\hline
\end{tabular}

${ }^{a}$ Atomic ratio. 
Table 3. Organic content of selected as-prepared samples determined from CHNS and ICP-OES analyses and from TG results.

\begin{tabular}{|c|c|c|c|c|}
\hline \multirow[b]{2}{*}{ As-prepared sample } & \multicolumn{3}{|c|}{ Chemical CHNS and ICP analyses } & \multirow{2}{*}{$\begin{array}{l}\text { TG } \\
\text { Organic }^{l} \\
(w t \%)\end{array}$} \\
\hline & $\begin{array}{l}{\left[\mathrm{C}_{2} \mathrm{C}_{1} \mathrm{im}\right]\left[\mathrm{Tf}_{2} \mathrm{~N}\right]} \\
(w t \%)\end{array}$ & $\begin{array}{l}{\left[\mathrm{C}_{2} \mathrm{C}_{1} \mathrm{im}\right][\mathrm{Cl}]} \\
(w t \%)\end{array}$ & $\operatorname{Org} /(A l+P)^{a}$ & \\
\hline AlP-0Py-14d & 7.09 & 27.39 & 0.22 & 42.32 \\
\hline AlP-0Py-28d & 4.77 & 25.27 & 0.18 & 41.06 \\
\hline AlP-0Py-14d-NH & 4.64 & 30.38 & 0.22 & 48.26 \\
\hline AlP-0Py-28d-NH & 6.84 & 20.96 & 0.14 & 36.45 \\
\hline
\end{tabular}

\footnotetext{
${ }^{a}$ Molar ratio between the organic species $\left(\left[\mathrm{C}_{2} \mathrm{C}_{1} \mathrm{im}\right]^{+}\left[\mathrm{Tf}_{2} \mathrm{~N}\right]^{-}\right.$and $\left.\left[\mathrm{C}_{2} \mathrm{C}_{1} \mathrm{im}\right]^{+} \mathrm{Cl}^{-}\right)$content estimated from the CHNS analysis and the phosphorus and aluminum content of the material determined by ICP-OES.

${ }^{\mathrm{b}}$ Weight loss in the TG analysis performed in an air flow from 25 to $900^{\circ} \mathrm{C}$.
} 
Table 4. Total weight loss in the TG performed in an air flow from 25 to $900^{\circ} \mathrm{C}$ for the as-prepared samples prepared in the presence of pyrrolidine.

\begin{tabular}{ll}
\hline As-prepared sample & Total weight loss(wt\%) \\
\hline AlP-1Py-14d & 34.33 \\
AlP-1Py-28d & 31.97 \\
AlP-1Py-14d-NH & 29.15 \\
AlP-1Py-28d-NH & 29.12 \\
AlP-2Py-14d & 37.06 \\
AlP-2Py-28d & 34.64 \\
AlP-2Py-14d-NH & 30.82 \\
AlP-2Py-28d-NH & 29.92 \\
\hline
\end{tabular}


Table 5. Specific surface area, external surface, micropore area, pore volume and average pore diameter of the ammonia heat-treated samples.

\begin{tabular}{|c|c|c|c|c|c|}
\hline $\begin{array}{l}\text { Ammonia heat-treated } \\
\text { sample }\end{array}$ & $\begin{array}{l}\mathrm{S}_{\mathrm{BET}} \\
\left(\mathrm{m}^{2} / \mathrm{g}\right)\end{array}$ & $\begin{array}{l}\mathrm{S}_{\mathrm{ext}}^{\mathrm{a}} \\
\left(\mathrm{m}^{2} / \mathrm{g}\right)\end{array}$ & $\begin{array}{l}\mathrm{S}_{\text {micro }} \mathrm{b} \\
\left(\mathrm{m}^{2} / \mathrm{g}\right)\end{array}$ & $\begin{array}{l}\mathrm{V}_{\mathrm{p}}^{\mathrm{c}} \\
\left(\mathrm{cm}^{3} / \mathrm{g}\right)\end{array}$ & $\begin{array}{l}\text { Average pore } \\
\text { diameter }(\mathrm{nm})\end{array}$ \\
\hline AlP-0Py-14d & 113 & 95 & 18 & 0.59 & 19.7 \\
\hline AlP-0Py-28d & 103 & 82 & 21 & 0.60 & 22.8 \\
\hline AlP-0Py-14d-NH & 229 & 199 & 30 & 1.06 & 17.0 \\
\hline AlP-0Py-28d-NH & 133 & 119 & 14 & 0.60 & 16.1 \\
\hline AlP-1Py-14d & 139 & 118 & 21 & 0.50 & 13 \\
\hline AlP-1Py-28d & 154 & 134 & 20 & 0.53 & 12 \\
\hline AlP-1Py-14d-NH & 113 & 104 & 9 & 0.47 & 15 \\
\hline AlP-1Py-28d-NH & 94 & 81 & 13 & 0.41 & 17 \\
\hline AlP-2Py-14d & 136 & 133 & 3 & 0.35 & 9 \\
\hline AlP-2Py-28d & 140 & 135 & 5 & 0.38 & 9 \\
\hline AlP-2Py-14d-NH & 46 & 43 & 3 & 0.17 & 14 \\
\hline AlP-2Py-28d-NH & 65 & 60 & 5 & 0.24 & 14 \\
\hline
\end{tabular}

${ }^{a}$ Non-micropore (external and mesopore) surface area.

${ }^{\mathrm{b}}$ Micropore surface area.

${ }^{\mathrm{c}}$ Pore volume. 
Table 6. Binding energy (B.E.) of Al 2p, $\mathrm{P} 2 \mathrm{p}$ and $\mathrm{O}$ 1s core-levels and composition determined by XPS.

\begin{tabular}{|c|c|c|c|c|c|c|c|}
\hline \multirow{2}{*}{$\begin{array}{l}\text { Ammonia heat- } \\
\text { treated sample }\end{array}$} & \multicolumn{3}{|c|}{ B.E. $(e V)$} & \multicolumn{4}{|c|}{ Composition (molar ratio) } \\
\hline & $A l 2 p$ & $P 2 p$ & $O 1 s$ & $P / A l$ & $N / P$ & $O /(P+A l)$ & $(N+O) /(P+A l)$ \\
\hline$A l P-O P y-28 d$ & 74.8 & 133.7 & 531.9 & 1.67 & 0.89 & 1.60 & 2.16 \\
\hline$A l P-O P y-28 d-N H$ & 74.7 & 133.8 & 531.9 & 1.04 & 0.80 & 1.61 & 2.02 \\
\hline$A l P-1 P y-14 d$ & 74.6 & 133.9 & 531.9 & 1.06 & 0.32 & 1.94 & 2.11 \\
\hline$A l P-1 P y-14 d-N H$ & 74.6 & 133.8 & 531.9 & 1.34 & 0.60 & 1.88 & 2.23 \\
\hline$A l P-2 P y-14 d$ & 74.5 & 133.8 & 532.0 & 1.03 & 0.33 & 1.93 & 2.10 \\
\hline$A l P-2 P y-14 d-N H$ & 74.5 & 133.4 & 531.9 & 1.88 & 0.89 & 1.52 & 2.12 \\
\hline
\end{tabular}

Table 7. Binding energy (B.E.) and relative contribution of N1s components of the XPS spectra.

\begin{tabular}{|c|c|c|c|c|c|c|}
\hline \multirow{2}{*}{$\begin{array}{l}\text { Ammonia heat-treated } \\
\text { sample }\end{array}$} & \multicolumn{2}{|c|}{ Component 1} & \multicolumn{2}{|c|}{ Component 2} & \multicolumn{2}{|c|}{ Component 3} \\
\hline & B.E. $(e V)$ & $\%$ & B.E. $(e V)$ & $\%$ & B.E. $(e V)$ & $\%$ \\
\hline AlP-0Py-28d & 401.5 & 7.54 & 398.9 & 68.97 & 397.3 & 23.48 \\
\hline AlP-0Py-28d-NH & 401.6 & 7.94 & 399.0 & 62.52 & 397.5 & 29.53 \\
\hline AlP-1Py-14d & 401.6 & 27.7 & 399.4 & 68.3 & 396.9 & 4.0 \\
\hline AlP-1Py-14d-NH & 401.6 & 11.4 & 399.1 & 77.0 & 397.1 & 11.6 \\
\hline AlP-2Py-14d & 401.7 & 17.7 & 399.3 & 76.7 & 397.1 & 5.6 \\
\hline AlP-2Py-14d-NH & 401.3 & 5.1 & 398.7 & 63.3 & 397.1 & 31.6 \\
\hline
\end{tabular}


Table 8. Shift of the N-H stretching mode of pyrrole upon adsorption on AlPON materials.

\begin{tabular}{ll}
\hline Sample & $\Delta v\left(\mathrm{~cm}^{-1}\right)$ \\
\hline AlP-0Py-28d & -83 \\
AlP-0Py-28d-NH & -90 \\
AlP-2Py-14d-NH & -90 \\
\hline
\end{tabular}

Table 9. Activity of ALPON materials for the Michael addition reaction between chalcone and malononitrile.

\begin{tabular}{|c|c|c|c|c|c|c|c|}
\hline \multirow{3}{*}{ Sample } & \multirow{3}{*}{$\begin{array}{l}S_{B E T} \\
\left(m^{2} / g\right)\end{array}$} & \multicolumn{2}{|c|}{$t=15 \min$} & \multicolumn{2}{|c|}{$t=30 \mathrm{~min}$} & \multicolumn{2}{|c|}{$t=7$ hours } \\
\hline & & Yield & & Yield $^{a}$ & & Yield $^{a}$ & \\
\hline & & $(\%)$ & Yield/S $S_{B E T}$ & $(\%)$ & Yield $/ S_{B E T}$ & $(\%)$ & Yield $/ S_{B E T}$ \\
\hline AlP-2Py-14d-NH & 46 & 3 & 0.06 & 8 & 0.17 & 29 & 0.63 \\
\hline AlP-0Py-28d & 103 & 16 & 0.15 & 25 & 0.24 & 63 & 0.61 \\
\hline AlP-0Py-28d-NH & 133 & 19 & 0.14 & 28 & 0.21 & 58 & 0.43 \\
\hline AlP-2Py-14d & 136 & 21 & 0.15 & 33 & 0.24 & 71 & 0.52 \\
\hline
\end{tabular}

${ }^{\text {a }}$ Reaction conditions: Chalcone/malononitrile molar ratio: 1 , catalyst/chalcone weight ratio: 0.04 ; chalcone/solvent weight ratio: 0.05 , reaction temperature: $60^{\circ} \mathrm{C}$. 


\section{FIGURE CAPTIONS}

Fig. 1. ATR-FTIR spectra of the as-prepared samples obtained in the absence of pyrrolidine: (a) AlP-0Py-14d, (b) AlP-0Py-14d-NH, (c) AlP-0Py-28d and (d) AlP-0Py28d-NH.

Fig. 2. ATR-FTIR spectra of the as-prepared samples prepared in the presence of pyrrolidine: (a) AlP-1Py-14d, (b) AlP-1Py-28d, (c) AlP-2Py-14d, (d) AlP-2Py-28d, (e) AlP-1Py-14d-NH, (f) AlP-1Py-28d-NH, (g) AlP-2Py-14d-NH and (h) AlP-2Py-28dNH.

Fig. 3. ATR-FTIR spectra of the ammonia heat-treated samples prepared in the absence of pyrrolidine: (a) AlP-0Py-14d, (b) AlP-OPy-28d, (c) AlP-0Py-14d-NH and (d) AlPOPy-28d-NH.

Fig. 4. Total pore volume of the ammonia heat-treated samples vs weight loss referred to the $\%$ TG residue determined by the TG analyses of the as-prepared samples.

Fig. 5. ${ }^{31}$ P MAS NMR spectra of some selected ammonia heat-treated samples: (a) AlPOPy-28d, (b) AlP-OPy-28d-NH and (c) AlP-2Py-14d.

Fig. 6. ${ }^{27} \mathrm{Al}$ MAS NMR spectra of some selected ammonia heat-treated samples: (a) AlP-0Py-28d, (b) AlP-0Py-28d-NH and (c) AlP-2Py-14d.

Fig. 7. N 1s XPS spectra of some selected ammonia heat-treated samples: (a) AlP-1Py14d, (b) AlP-2Py-14d, (c) AlP-1Py-14d-NH, (d) AlP-2Py-14d-NH, (e) AlP-0Py-28d and (f) AlP-0Py-14d-NH. 
Fig. 8. Specific surface area of the ammonia heat-treated samples vs. fraction of terminal P-NH 2 groups determined as the $\%$ XPS area of the N1s component at $401 \mathrm{eV}$.

Fig. 9. FTIR spectra of AlPON samples AlP-0Py-28d (A), AlP-0Py-28d-NH (B) and AlP-2Py-14d-NH (C) heat-treated under ammonia. Top: spectra of samples after degassing at $150^{\circ} \mathrm{C}$ (a) and in contact with pyrrole vapor at $25^{\circ} \mathrm{C}$ and equilibrium pressure of ca. 1 mbar (b) and ca. 10 mbar (c). Bottom: difference spectra c-a and b-a. Arrows indicate the shift of the $v(\mathrm{NH})$ band of pyrrole respect to pyrrole vapor $(3530$ $\mathrm{cm}^{-1}$ ) owing to $\mathrm{H}$-bonding with basic sites. The asterisk designates the band at 3410 $\mathrm{cm}^{-1}$ corresponding to physisorbed pyrrole [30] that becomes dominant at high equilibrium pressure.

Fig. 10. Yield of the 1,4 - addition product vs reaction time of the ammonia heat-treated catalysts AlP-2Py-14d (a), AlP-0Py-28d-NH (b), AlP-0Py-28d (c) and AlP-2Py-14d$\mathrm{NH}$ (d). Reaction conditions: temperature $=60^{\circ} \mathrm{C}$, chalcone/malononitrile molar ratio $=$ 1 , catalyst $/$ chalcone weight ratio $=0.04$, chalcone/methanol weight ratio $=0.05$.

Fig. 11. Influence of the specific surface area of the catalyst on the yield of the 1,4-addition product after 30 min of reaction for the ammonia heat-treated samples AlP2Py-14d (a), AlP-0Py-28d-NH (b), AlP-0Py-28d (c) and AlP-2Py-14d-NH (d). Reaction conditions: temperature $=60^{\circ} \mathrm{C}$, chalcone $/$ malononitrile molar ratio $=1$, catalyst $/$ chalcone weight ratio $=0.04$, chalcone $/$ methanol weight ratio $=0.05$. 
Figure 1

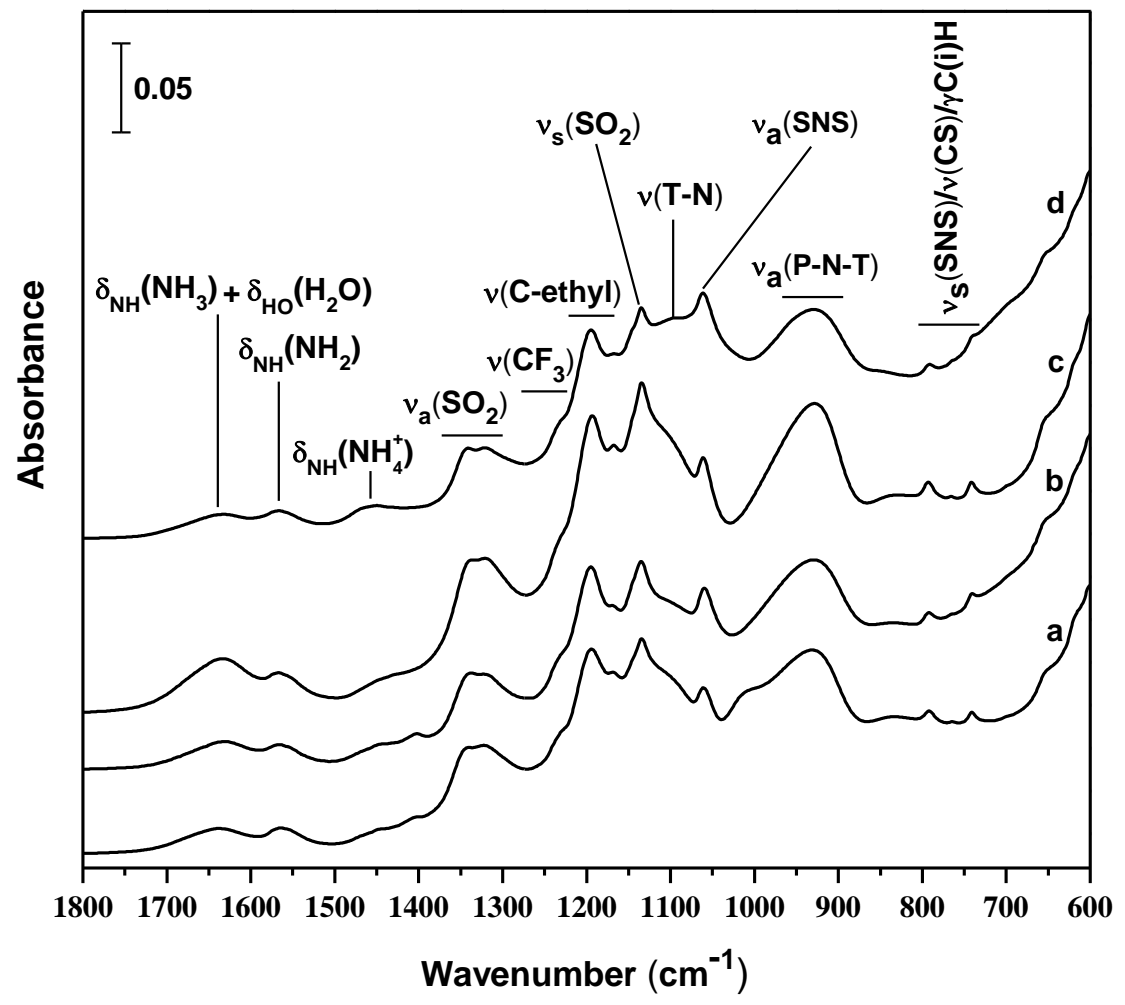


Figure 2

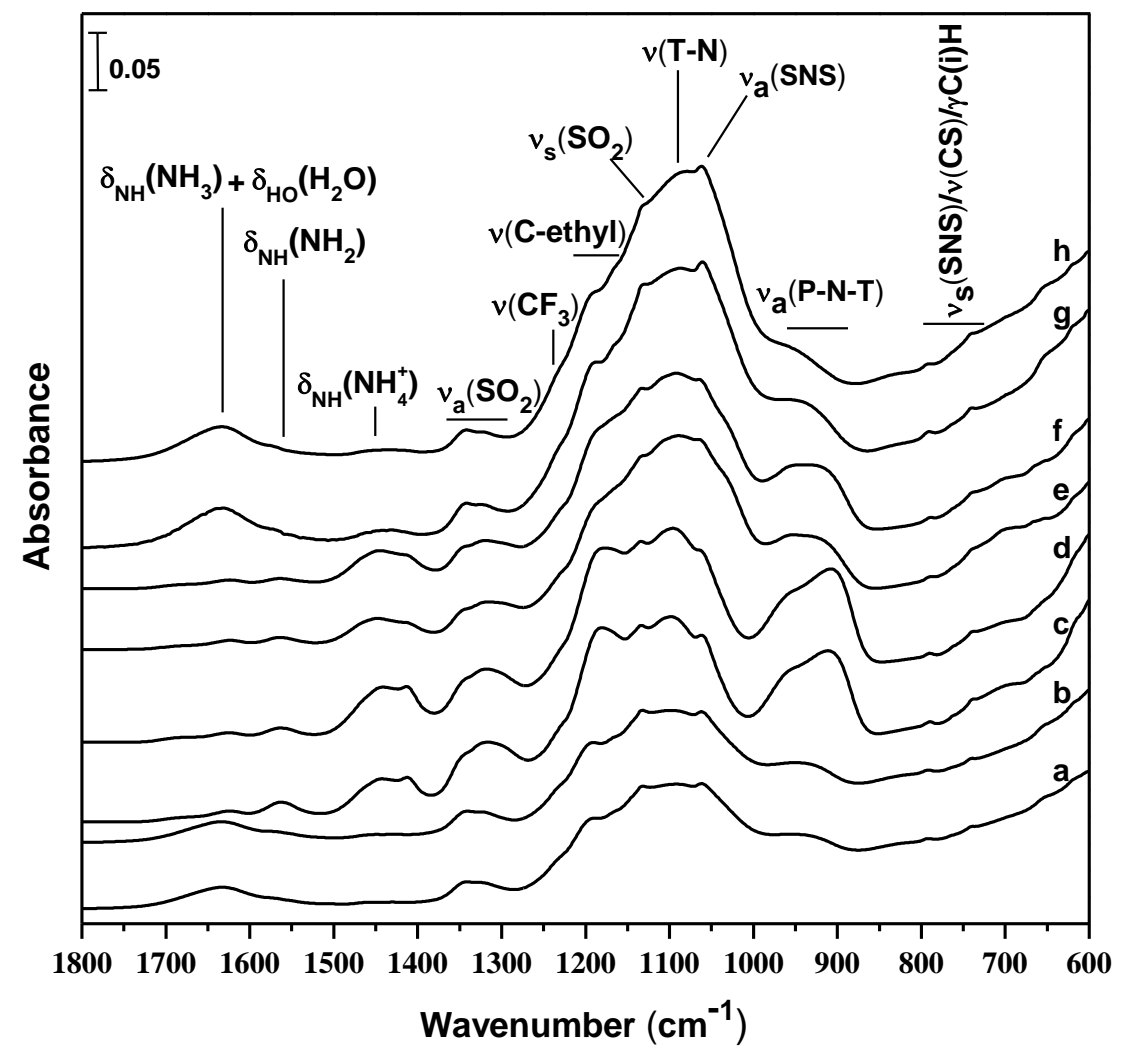


Figure 3

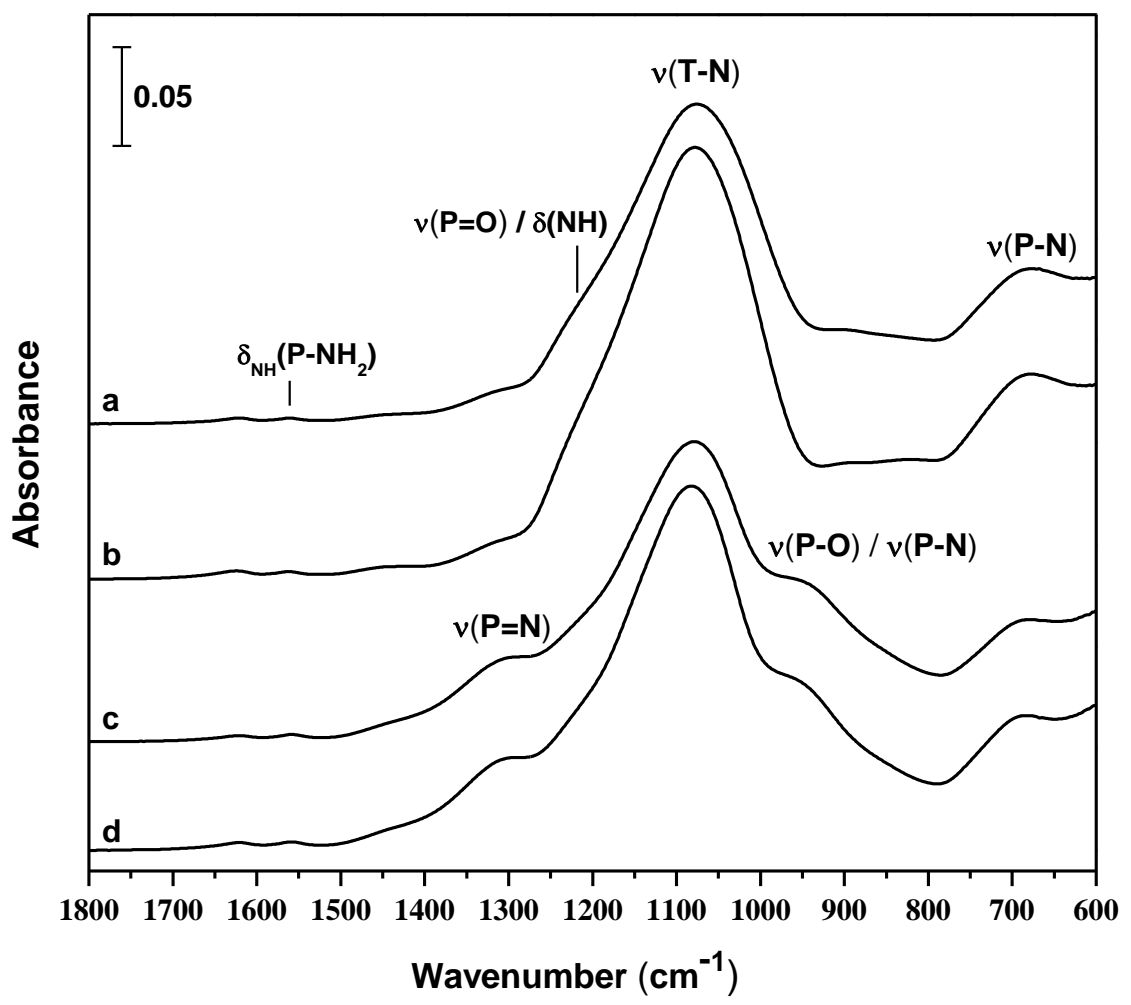


Figure 4

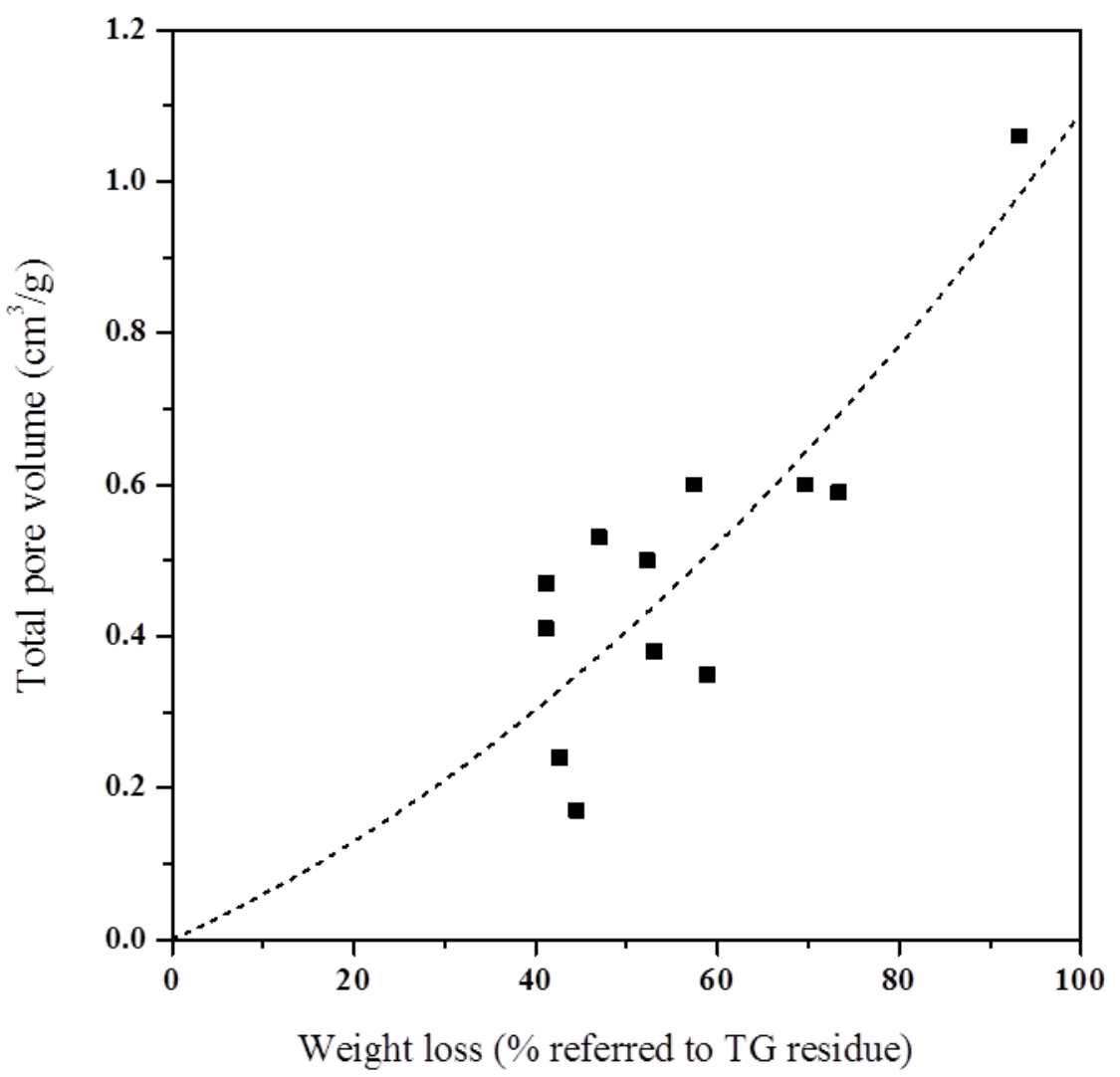


Figure 5

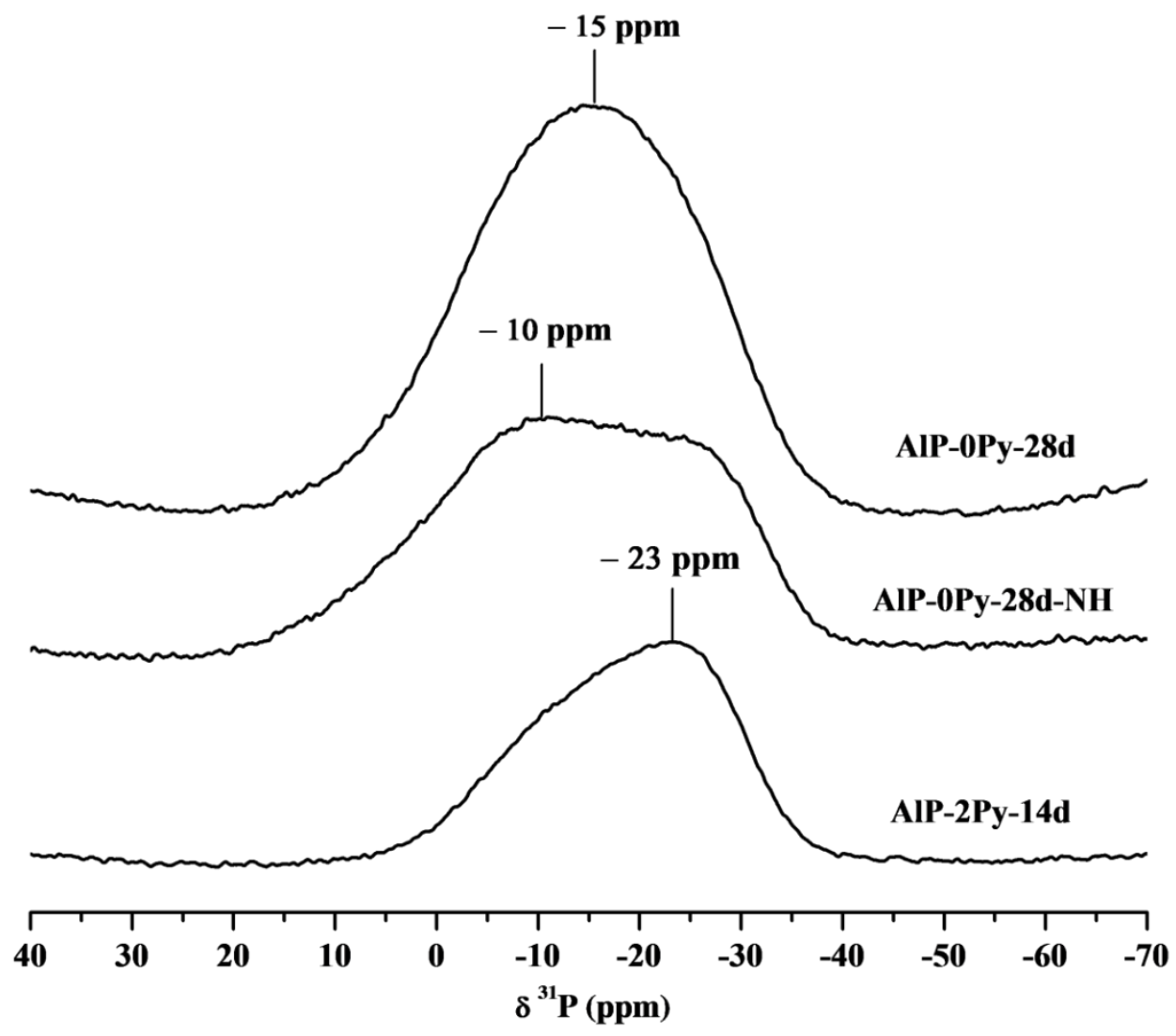


Figure 6

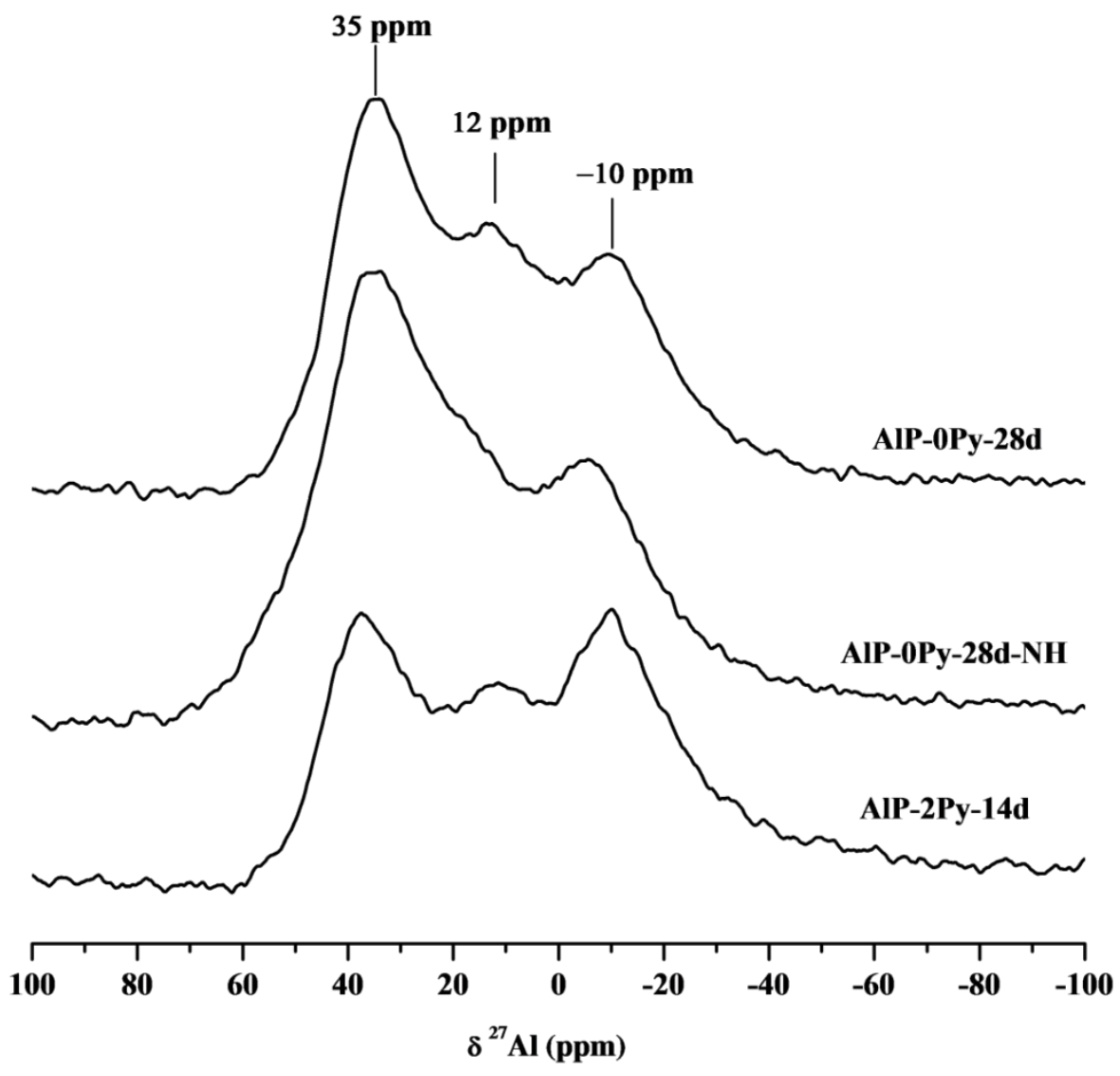


Figure 7
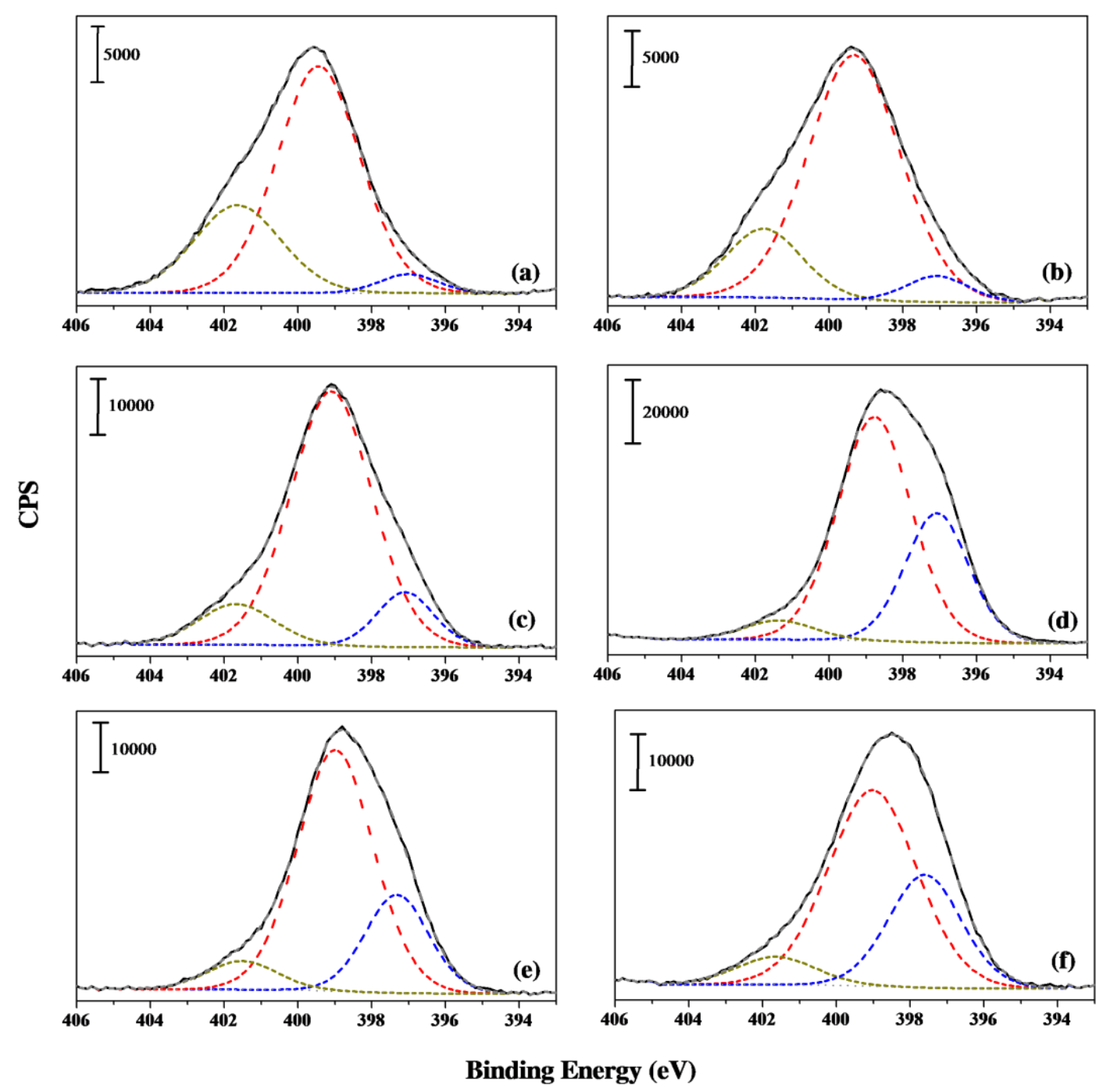
Figure 8

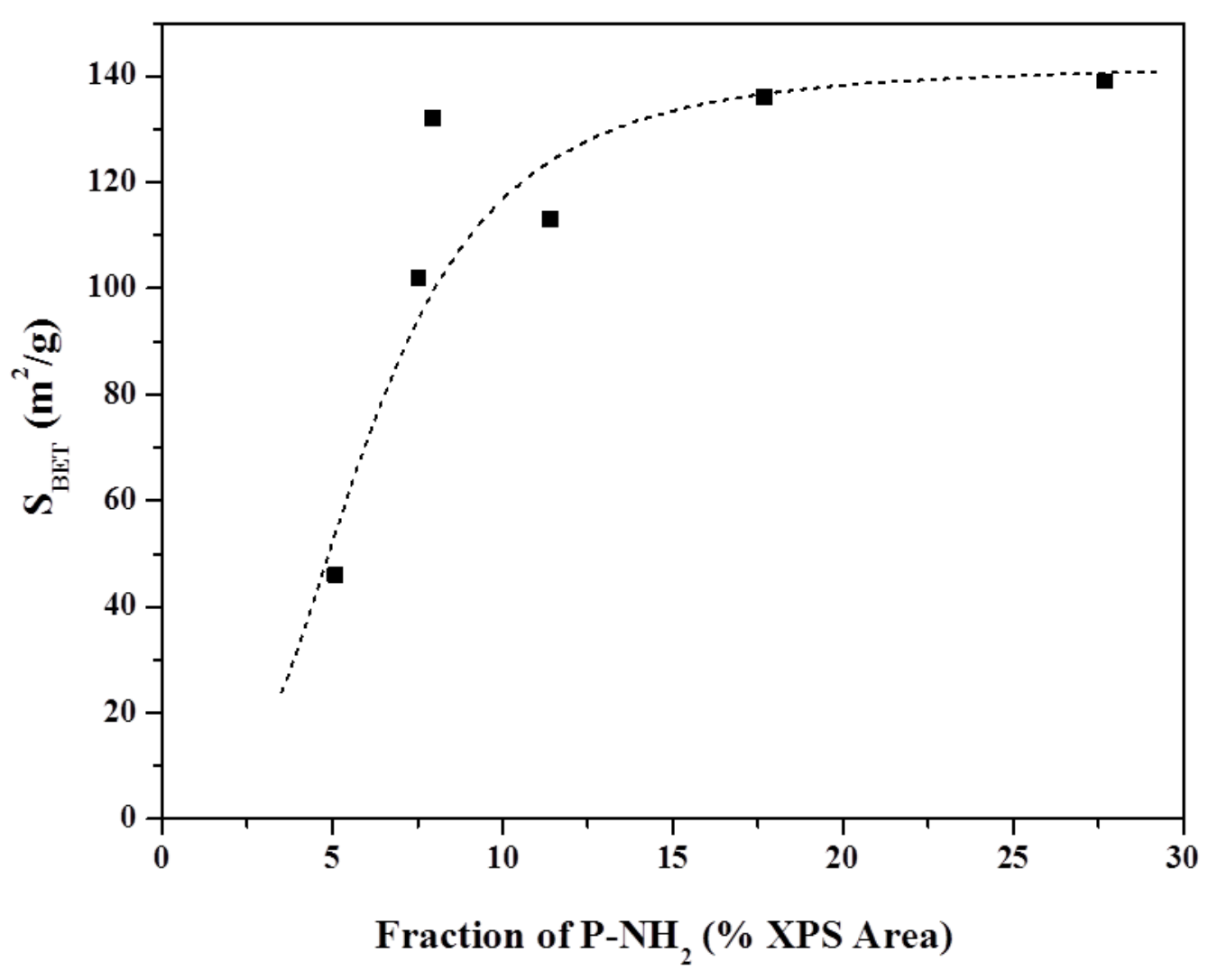


Figure 9

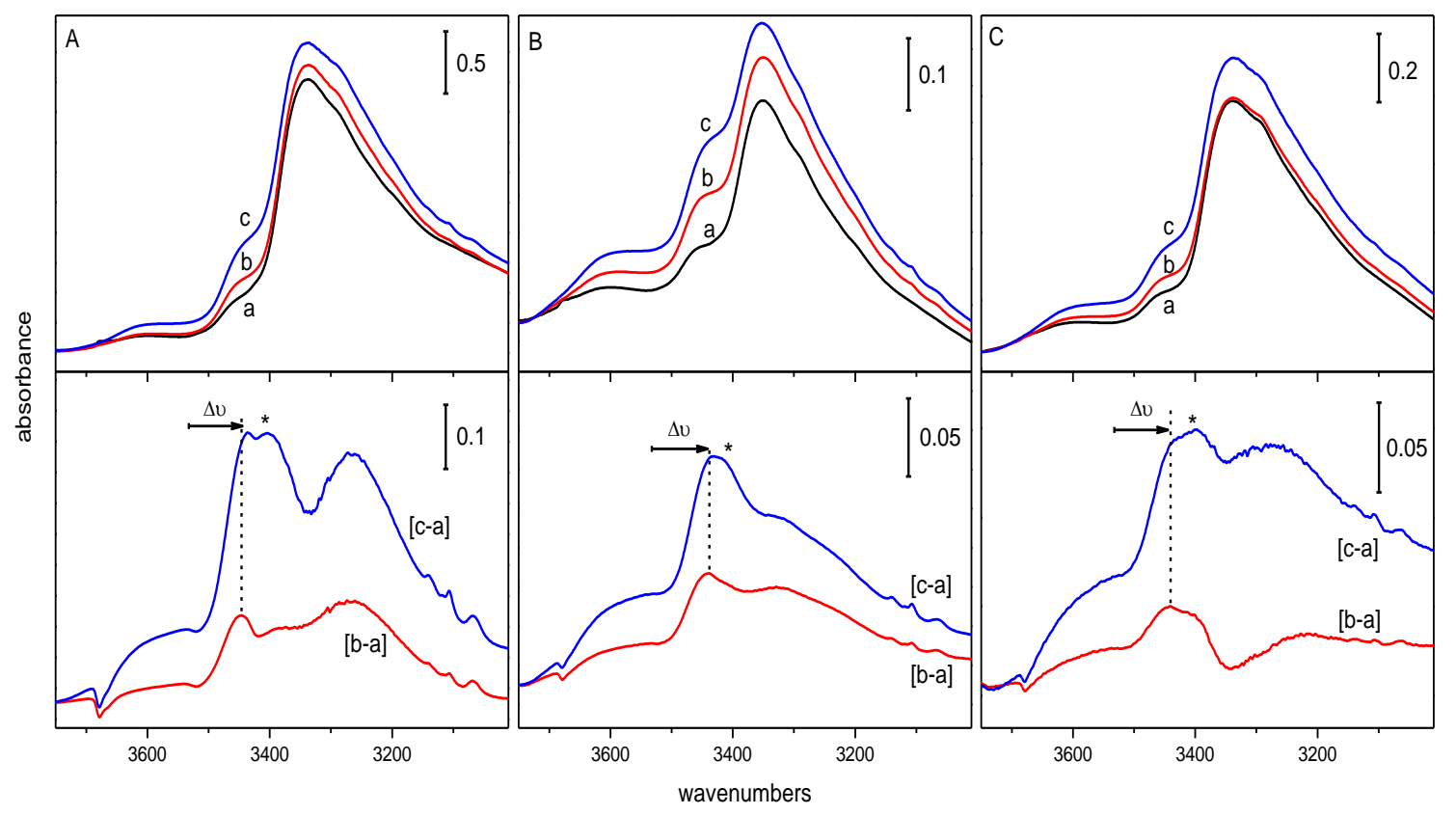


Figure 10

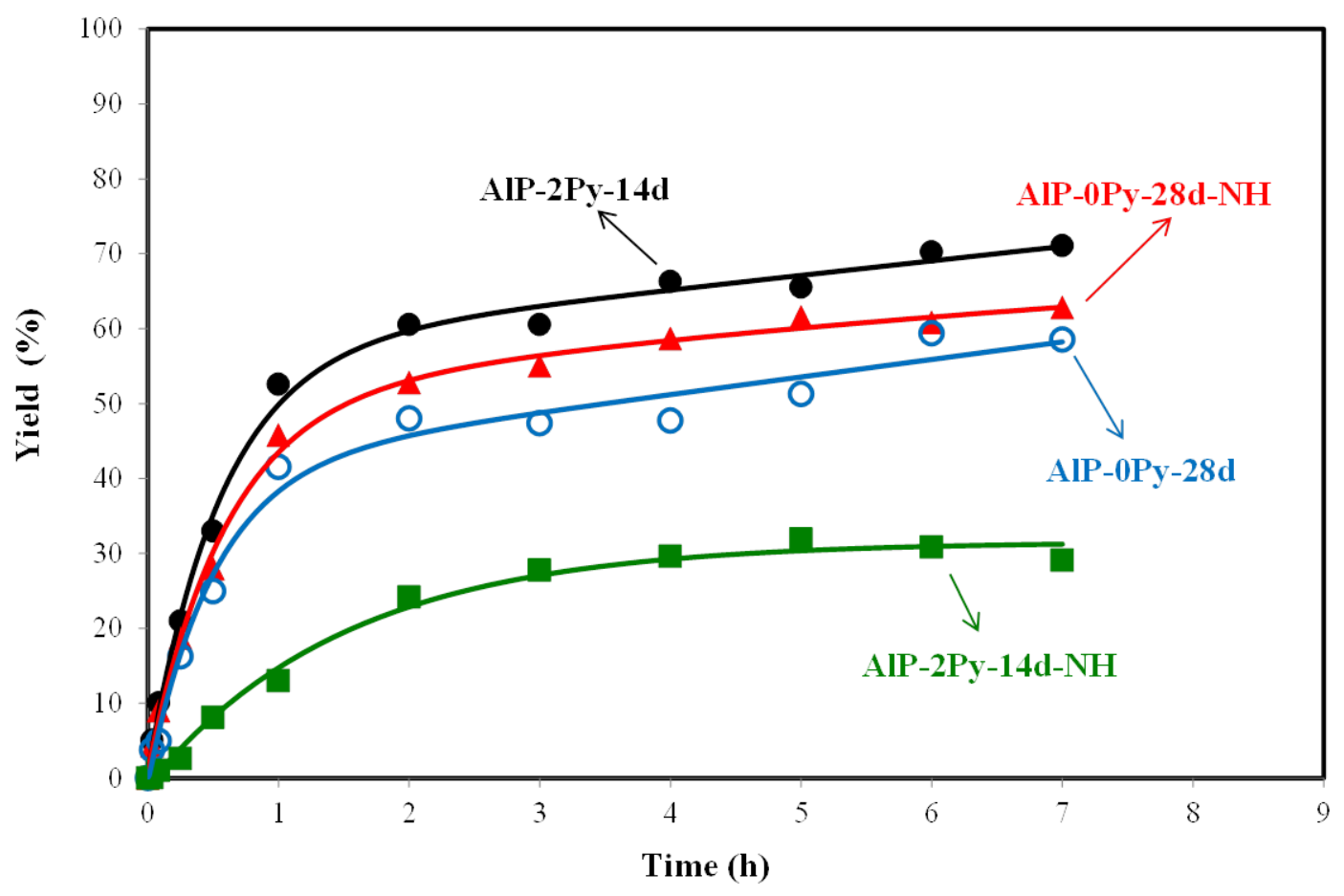


Figure 11

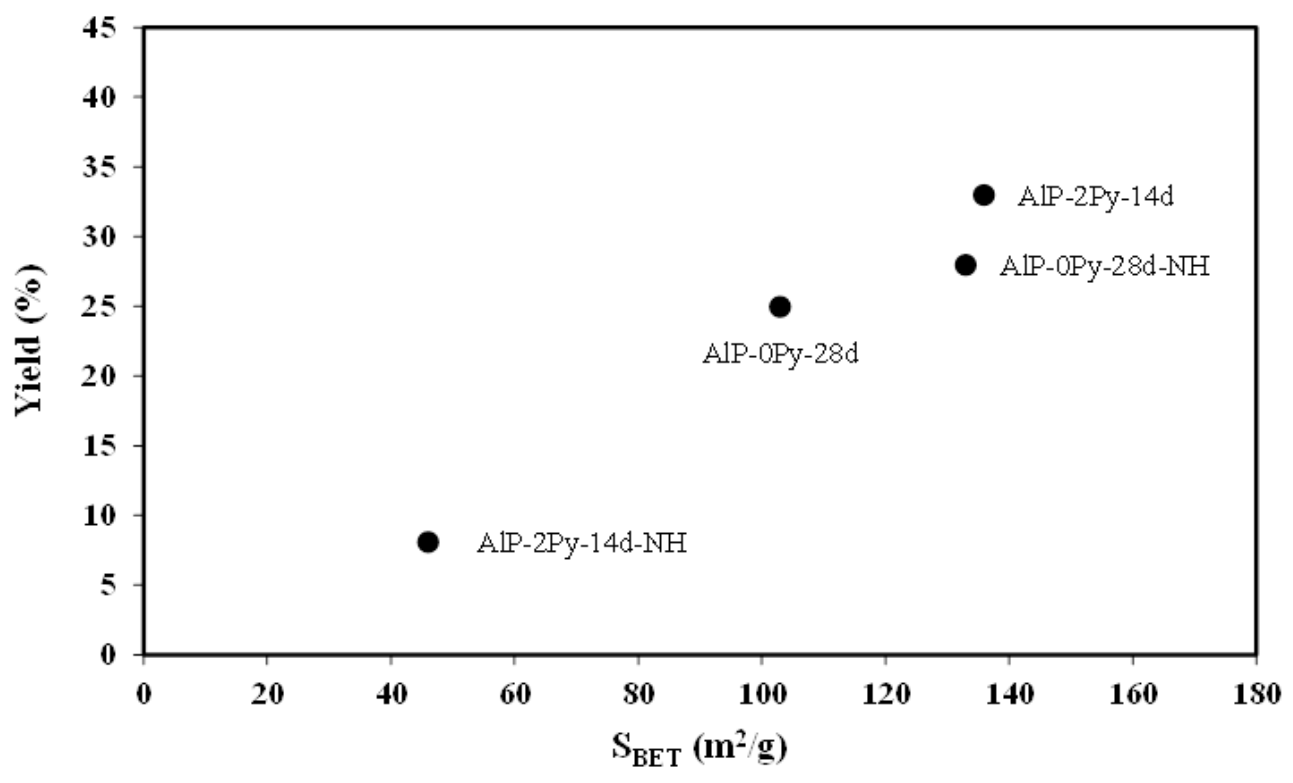

